\title{
Combinatorial engineering of N-TIMP2 variants that selectively inhibit MMP9 and MMP14 function in the cell
}

\author{
Valeria Arkadash ${ }^{1}$, Evette S. Radisky ${ }^{2}$ and Niv Papo ${ }^{1}$ \\ ${ }^{1}$ Department of Biotechnology Engineering and the National Institute of Biotechnology in the Negev, Ben-Gurion University \\ of the Negev, Beer-Sheva, Israel \\ ${ }^{2}$ Department of Cancer Biology, Mayo Clinic Comprehensive Cancer Center, Jacksonville, Florida, USA \\ Correspondence to: Niv Papo, email: papo@bgu.ac.il \\ Keywords: binding specificity; directed evolution; matrix metalloproteinase; protease inhibitor; protein engineering \\ Received: March 07, $2018 \quad$ Accepted: July 21, $2018 \quad$ Published: August 10, 2018 \\ Copyright: Arkadash et al. This is an open-access article distributed under the terms of the Creative Commons Attribution License \\ 3.0 (CC BY 3.0), which permits unrestricted use, distribution, and reproduction in any medium, provided the original author and \\ source are credited.
}

\section{ABSTRACT}

Developing selective inhibitors for proteolytic enzymes that share high sequence homology and structural similarity is important for achieving high target affinity and functional specificity. Here, we used a combination of yeast surface display and dual-color selective library screening to obtain selective inhibitors for each of the matrix metalloproteinases (MMPs) MMP14 and MMP9 by modifying the non-specific $\mathrm{N}$-terminal domain of the tissue inhibitor of metalloproteinase-2 (N-TIMP2). We generated inhibitor variants with 30- to 1175-fold improved specificity to each of the proteases, respectively, relative to wild type N-TIMP2. These biochemical results accurately predicted the selectivity and specificity obtained in cell-based assays. In U87MG cells, the activation of MMP2 by MMP14 was inhibited by MMP14-selective blockers but not MMP9-specific inhibitors. Target specificity was also demonstrated in MCF-7 cells stably expressing either MMP14 or MMP9, with only the MMP14specific inhibitors preventing the mobility of MMP14-expressing cells. Similarly, the mobility of MMP9-expressing cells was inhibited by the MMP9-specific inhibitors, yet was not altered by the MMP14-specific inhibitors. The strategy developed in this study for improving the specificity of an otherwise broad-spectrum inhibitor will likely enhance our understanding of the basis for target specificity of inhibitors to proteolytic enzymes, in general, and to MMPs, in particular. We, moreover, envision that this study could serve as a platform for the development of next-generation, target-specific therapeutic agents. Finally, our methodology can be extended to other classes of proteolytic enzymes and other important target proteins.

\section{INTRODUCTION}

A key feature of protein-protein interactions (PPIs) with implications for both basic and applied research is the binding specificity of the interacting proteins, a property largely determined by those residues found at the interface between the two interacting polypeptides [1-3]. As the binding specificity of a protein determines its affinity to a single partner from a population of multiple targets, the ability to accurately manipulate such specificity is crucial both for understanding the mechanisms of specific PPIs and for protein engineering purposes, such as for designing specific binders and/or inhibitors of target proteins [4-7].

Methods for acquiring target specificity typically include computational approaches and mutating predicted/candidate residues and testing the resulting changes on the affinity of the protein to its specific target [8-11]. Despite considerable advances in recent years [12-15], especially the significant clinical success of target-specific therapeutic antibodies [16-19], currently available computational methods for delineating the specificity of PPIs remain lacking. As such, our ability 
to develop specific/selective inhibitors for clinically important proteins, for example, continues to be limited. Predicting the specificity of protein-protein interactions is more complex than predicting affinity. While specificity prediction requires both positive design (i.e., stabilization of the desired complex) and negative design (i.e., destabilization of unwanted complexes), affinity prediction considers only positive design $[10,20]$. For instance, computationally saturated mutagenesis and similar classical approaches focus chiefly on single targets (namely, stabilization of the desired complex) and only allow for testing the effects of single mutations $[1,3,9,21,22]$. Predicting specificity by these methods is, therefore, time-consuming and laborious, as separate computations are required for all possible targets. Moreover, assessing acquired specificity calls for protein purification, sometimes of a large number of mutants $[3,9,10]$, followed by binding affinity measurements for each mutant. Additional limitations of classical computational approaches for predicting specificity are inaccuracy in energy calculations due to limited sampling of possible conformational changes [23, 24] and often a failure to consider the energy of hydrogen bond formation with the solvent $[12,25]$. Furthermore, mutations to proline and glycine cannot be considered by such methods, given that these mutations are likely to induce backbone conformational changes that cannot be modeled with in silico protocols [3]. Thus, experimentally testing the various variants that are possible so as to assess changes in specificity cannot be avoided.

With this in mind, approaches using protein-library display and selective sorting technologies that overcome some of the caveats listed above have been developed. For example, the yeast-surface display (YSD) platform, a powerful directed evolution protein engineering technology [26-31], rapidly explores all possible mutations, both single and multiple, and quantitatively screens for those binders with high target specificity [32-34]. However, in most of these methods, screening involves a fluorescently labeled target of interest in the presence of non-labeled competitor molecules [32], a scenario that could result in the selection of mutants that bind the desired target with high affinity but that also exhibit higher affinity for other targets [33]. Indeed, most currently available approaches generate high-affinity, yet not necessarily selective binders [35-37]. Moreover, in those studies that did generate selective binders, the specific inhibition of targets with high sequence and structural homology, especially within the cell, was not demonstrated.

With these considerations in mind, we have developed a dual-target selective library screen as the basis of a novel comprehensive single-step approach for identifying selective binders that strongly inhibit their targets in cells. In our strategy, two targets presenting highly similar structures and sharing a nearly identical ligand-binding epitope are fluorescently labeled using different dyes, with each target serving as a competitor for the other. In this manner, mutant binding partners that specifically interact with each target, namely variants that exhibit both high affinity to one target and low binding to the competitor target, can be identified.

In the current report, we employed our strategy to generate specificity in a non-selective matrix metalloproteinase (MMP) family inhibitor, tissue inhibitor of metalloproteinase 2 (TIMP2). TIMP2 is one of the four homologous mammalian TIMPs (TIMP1-4) that recognize the two human MMPs, MMP14 and MMP9 [38]. The inhibition of MMP proteases is of clinical value, as MMP14 and MMP9 are oncogenic [39-41]. MMP14 and MMP9 also exhibit anti-tumorigenic functions [42]. In breast carcinoma, for instance, MMP14 overexpression correlates with poor prognosis [43, 44]. Interestingly, MMP14 deficiency is lethal to mice, with MMP14 knockout mice suffering from severe abnormalities and dying shortly after birth $[45,46]$. MMP9, on the other hand, was shown to promote tumor formation when expressed in stromal cells but also correlated with favorable prognosis for patients when expressed in carcinoma cells [47]. In a mouse model of breast cancer based on MCF-7 cells that do not endogenously express MMP9 and into which an adenovirus vector containing the MMP9 gene was injected, tumor regression was induced [48]. This was probably due to the ability of MMP9 to induce the anti-angiogenic endostatin expression $[48,49]$. In addition, several mouse models have revealed that MMP9 deficiency increases tumor progression and invasiveness [50, 51]. At the same time, MMP14 and MMP9 fulfill additional physiologically important functions. MMP14 plays important roles in tissue regeneration and has been specifically linked with muscle renewal [52] and bone development [53]. MMP9 is important for brain development and plasticity [54]. Thus, both enzymes are involved in both pathophysiological and specific normal states, such that specific inhibition of each is crucial for therapeutics.

Like all MMP family members, MMP14 and MMP9 are multi-domain proteins that differ in domain architecture and substrate preference. However, all share a catalytic domain with a nearly identical active site containing a $\mathrm{Zn}$ ion. Because of the importance of MMPs in cancer, many MMP inhibitors have been designed in the past thirty years. Unfortunately, to date all have failed in clinical trials due to high toxicity $[55,56]$. A major reason for the failure of these MMP inhibitors is that they were often poorly soluble and designed to bind $\mathrm{Zn}$, such that they could not reach the desired target due to binding to $\mathrm{Zn}$ and other heavy metals in various other, unrelated proteins. In recent years, it has become clear that inhibitors with narrow or single MMP specificity hold much greater therapeutic potential than do broad specificity MMP inhibitors. Obtaining such specific inhibitors has, however, proven to be challenging. 
The two MMPs can be distinguished on the basis of their distinct functional groups, with MMP9 belonging to the gelatinases and MMP14 being a membrane-type MMP. Still, the development of specific inhibitors against either protease has been challenging, probably due to the highly similar structures of MMP14 and MMP9 $[57,58]$. However, as their X-ray structures are available, bioinformatics analysis of the interactions of MMP14 and MMP9 with TIMP2 is possible [59, 60]. Threedimensional structures of TIMP-MMP complexes [61-66] have revealed that binding of TIMP to MMP mostly occurs through the $\sim 125$ amino acid-long TIMP N-terminal domain (N-TIMP) [60, 61, 63-66]. Indeed, isolated N-TIMP is a potent inhibitor of various MMPs and has been repeatedly used in place of the full-length protein in various studies [67]. Moreover, the N-TIMP (MMP-binding) interface is highly tolerant to residue substitution or the incorporation of additional amino acids [68]. As the sequence of the N-TIMP2 interface largely determines the affinity and specificity of the inhibitor to its targets [3], introducing mutations in this region would enable us to simultaneously optimize both target affinity and specificity without compromising stability, the latter being mostly governed by scaffold (non-binding interface) residues.

In the present study, examination of the N-TIMP2MMP interface served to direct the introduction of mutations that generated N-TIMP2 variants showing improved selectivity and affinity to either MMP14 or MMP9, as evaluated in in vitro assays using purified proteins and in cell-based inhibition studies. We succeeded in generating an N-TIMP2 mutant library rich in affinityand specificity-enhancing mutations. Of these, we identified the most highly selective N-TIMP2 mutants, based on their ability to inhibit either of the two proteases. We, furthermore, validated our screening results in cellbased models of MMP-dependent breast cancer cellular migration, and evaluated and compared the abilities of selected purified N-TIMP2 variants to act as functional and selective MMP inhibitors in the cell. To the best of our knowledge, this is the first report of a platform offering an effective screen of TIMPs showing specificity towards particular MMPs, with validation of the selective inhibition in cells provided.

\section{RESULTS}

\section{Selective sorting of an N-TIMP2 library}

This study relied on the design schematically depicted in Figure 1A and 1B. Briefly, we incubated a YSD N-TIMP2 library with a mixture of MMP9 and MMP14 catalytic domains (MMP9 ${ }_{\mathrm{CAT}}$ and MMP14 ${ }_{\mathrm{CAT}}$, respectively). To evaluate the binding of members of the YSD N-TIMP2 library to either protease using fluorescence-activated cell sorting (FACS), each protease was labeled with a different fluorophore. Ideally, such sorting should reveal N-TIMP2 variants that bind exclusively to MMP14 ${ }_{\mathrm{CAT}}$ or MMP9 ${ }_{\mathrm{CAT}}$

As a first step, a focused N-TIMP2 library involving randomization at seven positions in the binding surface of N-TIMP2 [60], found at a distance of $4 \AA$ from MMP14 in the MMP14/TIMP2 complex [3, 60], was generated (Supplementary Figure 1). This region of TIMP2 was previously shown to well tolerate residue substitution or the incorporation of additional amino acids without compromising stability [68]. Taking this approach allowed for a reduction of the theoretical library size to $\sim 10^{8}$ candidates, a size which is tractable using our yeast surface display (YSD) technique. The library was expressed on a pCHA construct that had undergone an initial round of enrichment for that fraction of clones with high expression levels, as previously described [68]. For the selective binding sorts, MMP14 ${ }_{\mathrm{CAT}}$ and MMP9 ${ }_{\mathrm{CAT}}$, each labeled with a different fluorophore (labeled and unlabeled MMPs had similar catalytic activities, Supplementary Figure 2), were simultaneously added to the yeastdisplayed N-TIMP2 library (Figure 1A). In the first round of sorting, $1 \mu \mathrm{M}$ of MMP14 ${ }_{\mathrm{CAT}}$ conjugated to DyLight-488 was added together with $50 \mathrm{nM}$ of $\mathrm{MMP}_{\mathrm{CAT}}$ conjugated to DyLight-650. Two diagonal FACS gates were used to select binders in this sort (Figure 1B), yielding the MMP14 and MMP9 high binding populations. Next, four sequential sorts were performed on each population separately. To select MMP14 high affinity clones, the concentration of MMP14 ${ }_{\mathrm{CAT}}$ was decreased to $250 \mathrm{nM}$ in the second sort and down to $50 \mathrm{nM}$ in the final sort. Likewise, the concentration of $\mathrm{MMP}_{\mathrm{CAT}}$ was increased to $100 \mathrm{nM}$ in the second sort and up to $150 \mathrm{nM}$ in the final round of sorting. To select for MMP9 high affinity clones, the concentration of $\mathrm{MMP}_{\mathrm{CAT}}$ was decreased to $10 \mathrm{nM}$ in the second sort and down to $1 \mathrm{nM}$ in the final sort, while the concentration of MMP $14_{\mathrm{CAT}}$ remained at $1 \mu \mathrm{M}$. After each round of sorting, the populations were sequenced, confirming that specific mutations predominated in each population (Figure 2). In the flow cytometry analysis performed on the post-sort libraries, selective binding of each population to its designated target was confirmed (Figure 1C). After the fourth and final sort, no significant changes in binding affinity towards the targets were noted by flow cytometry analysis.

After sequencing the library obtained in the final sort, a few N-TIMP2 variants with selectivity to MMP9 and MMP14 were chosen. From the selected MMP14 high affinity binders, eight different mutants were identified, with a predominating mutation (termed N-TIMP2 ${ }_{147}$ ) repeating in five out of twelve sequences. The individual MMP14 binding clones were assessed for selective binding to MMP14 ${ }_{\mathrm{CAT}}$ over MMP9 ${ }_{\mathrm{CAT}}$ by flow cytometry (Figure 1D), with the ratio between the signal of binding to $\mathrm{MMP} 14_{\mathrm{CAT}}$ and the signal of binding to MMP9 ${ }_{\mathrm{CAT}}$ being determined and compared with that obtained using 
A

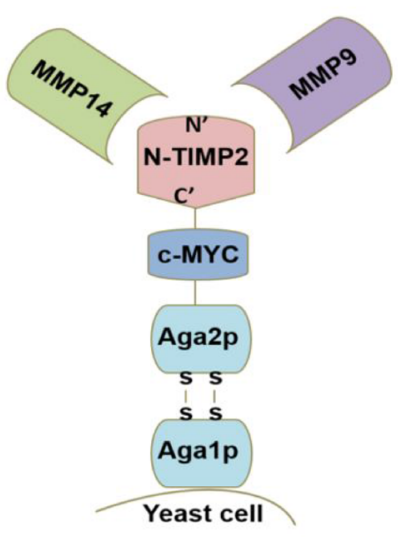

B

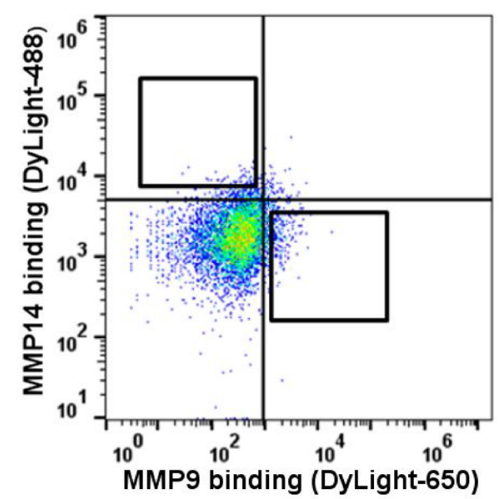

C

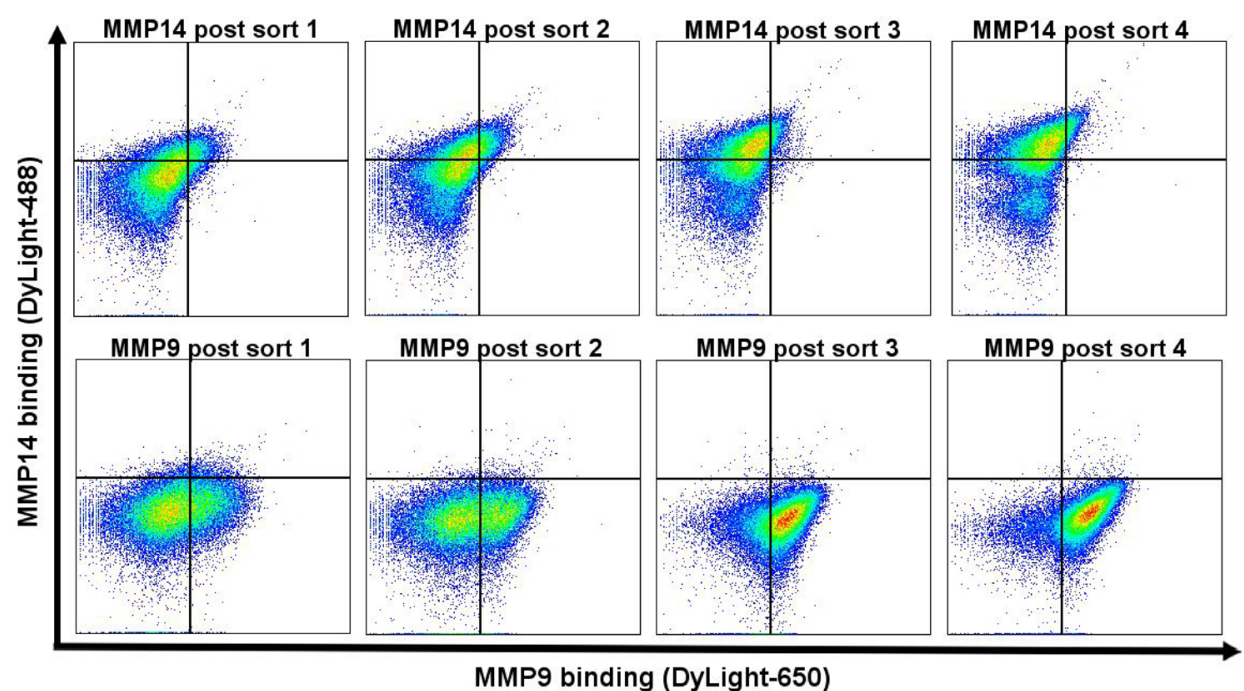

D

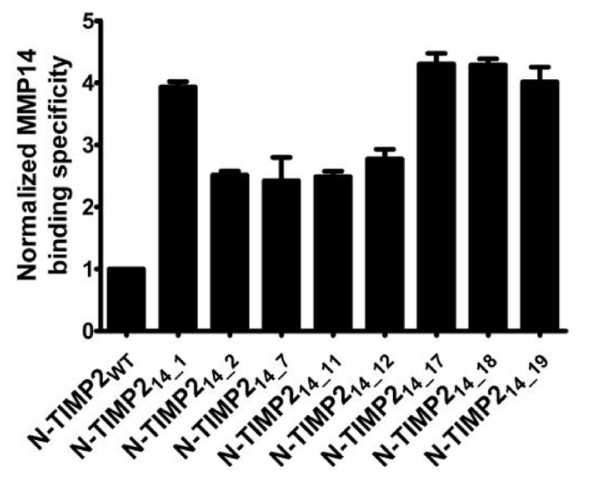

E

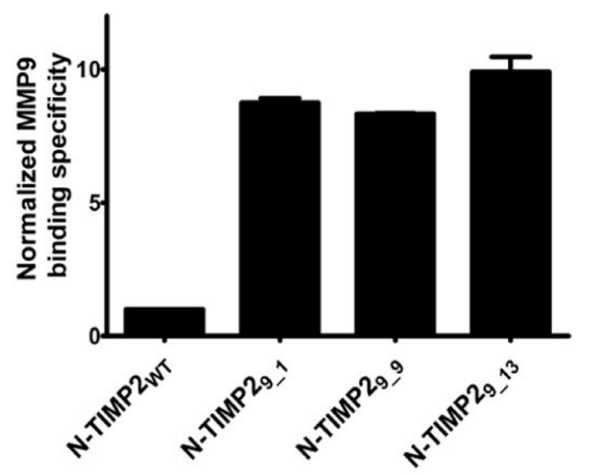

Figure 1: Selective library screening. (A) Schematic representation of N-TIMP2 expressed in a yeast surface display using a pCHA construct, with MMP-14 ${ }_{\mathrm{CAT}}$ and MMP9 ${ }_{\mathrm{CAT}}$ as soluble targets. (B) FACS sorting of the N-TIMP2 library using $1 \mu \mathrm{M}$ MMP14 ${ }_{\mathrm{CAT}}$ and 50 $\mathrm{nM}$ MMP9 ${ }_{\text {CAT }}$ as targets. The y-axis shows binding to MMP14 ${ }_{\mathrm{CAT}}$ conjugated to DyLight 488 , and the $\mathrm{x}$-axis shows binding to MMP9 ${ }_{\mathrm{CAT}}$ conjugated to DyLight-650. The squares indicate sort gates used to select the desired yeast cell populations. (C) Flow cytometry analysis of populations representing the four rounds of sorting using $500 \mathrm{nM} \mathrm{MMP14_{CAT }}$ and $50 \mathrm{nM} \mathrm{MMP9}{ }_{\mathrm{CAT}}$ as targets. (D) Normalized binding of individual clones with selective binding towards MMP14, identified after the fourth round of sorting. The analysis was performed using

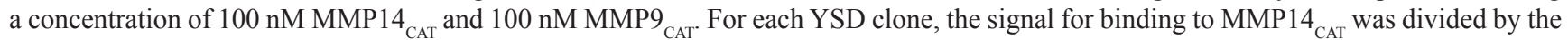
signal of binding to MMP9 ${ }_{\mathrm{CAT}}$ and the resulting ratio was normalized to the MMP1 ${ }_{\mathrm{CAT}} / \mathrm{MMP}_{\mathrm{CAT}}$ binding signal ratio of N-TIMP2 ${ }_{\mathrm{WT}}$ (E) Normalized binding of individual clones with selective binding towards MMP9, identified after the fourth round of sorting. The analysis was performed at concentration of $1 \mu \mathrm{M} \mathrm{MMP14_{CAT }}$ and $10 \mathrm{nM} \mathrm{MMP9} 9_{\mathrm{CAT}}$. Signals for binding towards MMP9 ${ }_{\mathrm{CAT}}$ were divided by the corresponding signals of binding to MMP14 $4_{\mathrm{CAT}}$ and the resulting ratio was normalized to the MMP9 ${ }_{\mathrm{CAT}} / \mathrm{MMP} 14_{\mathrm{CAT}}$ binding signal ratio of N-TIMP2 ${ }_{\text {WT }}$ 
N-TIMP $2_{\text {WT }^{*}}$ Two clones, N-TIMP2 ${ }_{14}{ }_{17}$ and N-TIMP2 ${ }_{14}{ }_{18}$, showed the highest specific binding towards MMP14 ${ }_{\mathrm{CAT}}$, as compared to N-TIMP $2_{\text {WT }}$ ( $\sim 5$-fold increase). As these clones showed the lowest binding towards MMP9 among clones with enhanced MMP14 affinity (Supplementary Figure 3), they were selected for purification and further examination. Of the MMP9 binders, three clones were identified, with clone $\mathrm{N}-\mathrm{TIMP} 2_{9}$, repeating in six of nine sequences (Table 1). We continued with clones N-TIMP2 ${ }_{9}$ and N-TIMP2 ${ }_{913}$ for production as soluble proteins, given that both showed $\sim 10$-fold higher selective binding towards MMP9, as compared to N-TIMP $2_{\text {WT }}$ (Figure 1E).

\section{Selective N-TIMP2 variants show improved specific in vitro inhibition of MMP14 ${ }_{\mathrm{CAT}}$ and MMP9 $_{\text {CAT }}$}

To examine the in vitro inhibition of MMP14 and MMP9 by the variants, these were expressed and purified in a soluble form in the yeast Pichia pastoris, as previously described [68]. Briefly, the variants were expressed from the pPICZ $\alpha \mathrm{A}$ vector that produces versions of the proteins with a free $\mathrm{N}$-terminus and $\mathrm{C}$-terminal Hisand c-Myc epitope tags. We purified the proteins using affinity chromatography, followed by size-exclusion chromatography (Figure 3A). The sizes and purity of the variants were confirmed by mass spectrometry and SDS-PAGE, respectively (Figure 3B, 3C). To determine the binding affinities of the purified selective N-TIMP2 variants towards MMP14 and MMP9, we performed an enzyme activity assay. Either MMP- $14_{\mathrm{CAT}}$ or $\mathrm{MMP}_{\mathrm{CAT}}$ were incubated with increasing concentrations of N-TIMP $2_{\text {WT }}$ (or N-TIMP2 mutants), and the cleavage of a fluorogenic substrate was determined as a function of time. The slope of each catalytic reaction was calculated and fitted to Morrison's tight binding equation (Eq. 1, see Methods) to determine the $K_{i}$ value (Figure 3D-3F, Table 2). N-TIMP2 ${ }_{\mathrm{WT}}$ inhibited MMP14 ${ }_{\mathrm{CAT}}$ and MMP9 ${ }_{\mathrm{CAT}}$ with $K_{i}$ values of $5 \mathrm{nM}$ and $0.5 \mathrm{nM}$, respectively (Table 2), a finding consistent with previous studies $[3,68]$. The two selective MMP14 inhibitors N-TIMP2 ${ }_{14} 17$ and N-TIMP2 ${ }_{1418}$ inhibited MMP14 ${ }_{\text {CAT }}$ with $K_{i}$ values of $30 \pm 3 \mathrm{pM}^{-}$and $24 \pm 5 \mathrm{pM}$, respectively. These values correspond to affinities for MMP14 ${ }_{\mathrm{CAT}}$ that were $\sim 200$-fold superior than N-TIMP $2_{\mathrm{wT}^{*}}$ The clones also showed 0.14- and 0.4-fold decreased affinity towards

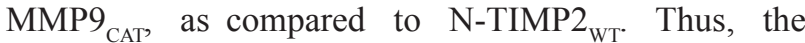
calculated specificities (i.e., fold affinity enhancement), of N-TIMP2 ${ }_{14} 17$ and N-TIMP2 ${ }_{14}{ }_{18}$ towards MMP14 ${ }_{\text {CAT }}$ over MMP9 ${ }_{\mathrm{CAT}}$, relative to N-TIMP ${ }_{\mathrm{WT}}$, were $\sim 1200$ and $\sim 500$, respectively. The selective MMP9 binding variants

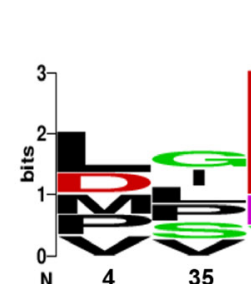

\section{MMP14}

Sort 2
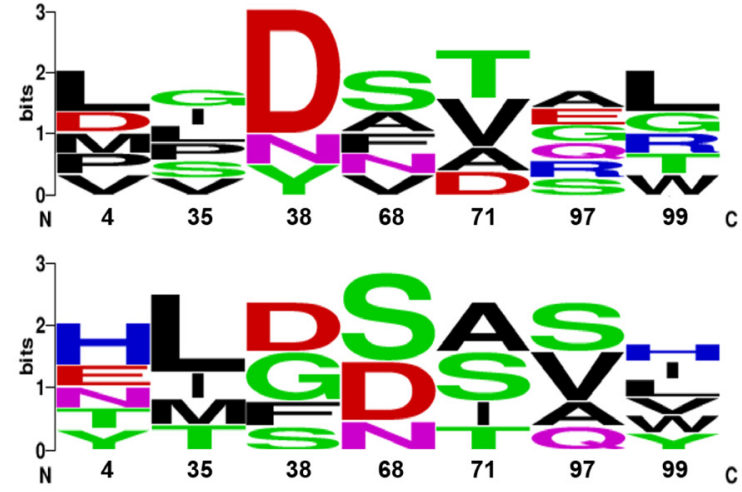

990

Sort 3
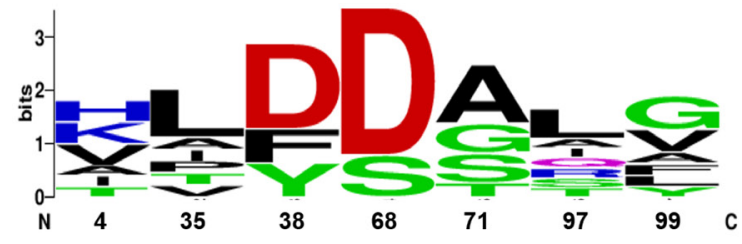

Sort 4

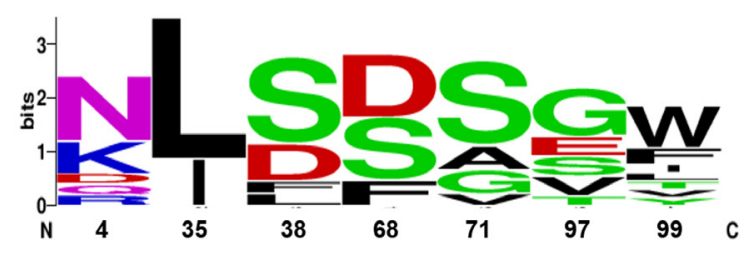

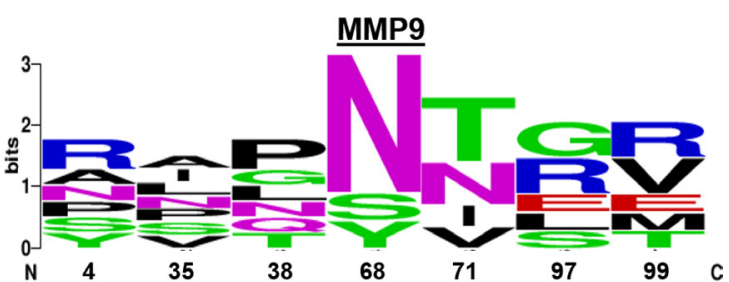
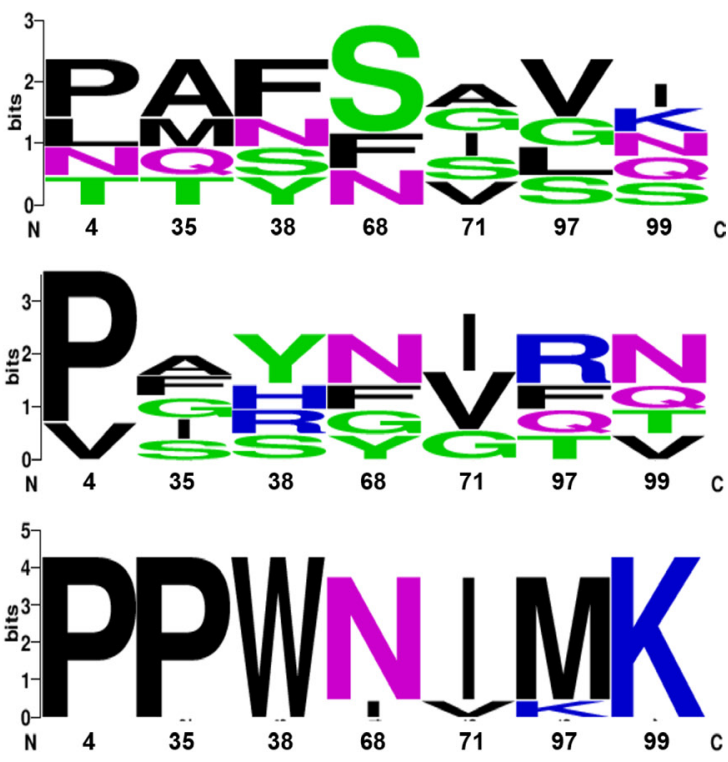

Figure 2: Logo summaries of the selective libraries sequenced after each selective round of sorting. The height of each letter is proportional to its frequency at that position. The total height of the stack represents conservation at that position. Green, purple, blue, red and black letters, respectively, represent polar, neutral, basic, acidic and hydrophobic amino acids. The position numbers of the residues are denoted at the bottom of the figure. The logos were generated by the WebLogo server (weblogo.berkeley.edu/logo.cgi). 
Table 1: Summary of sequences of selective variants obtained after the fourth round of sorting

\begin{tabular}{|c|c|c|c|c|c|c|c|}
\hline Clone/Position & 4 & 35 & 38 & 68 & 71 & 97 & 99 \\
\hline N-TIMP $2_{\text {wT }}$ & $\mathrm{S}$ & $\mathrm{I}$ & $\mathrm{N}$ & $\mathrm{S}$ & $\mathrm{V}$ & $\mathrm{H}$ & $\mathrm{T}$ \\
\hline N-TIMP2 ${ }_{14} 1$ & $\mathrm{~N}$ & $\mathrm{~L}$ & $\mathrm{~S}$ & $\mathrm{D}$ & $\mathrm{S}$ & $\mathrm{S}$ & $\mathrm{F}$ \\
\hline N-TIMP2 ${ }_{14 \_2}$ & $\mathrm{R}$ & I & $\mathrm{D}$ & $\mathrm{D}$ & A & $\mathrm{T}$ & $\mathrm{L}$ \\
\hline N-TIMP $2_{14 \_7}$ & $\mathrm{~N}$ & $\mathrm{~L}$ & $\mathrm{~S}$ & $\mathrm{~S}$ & $\mathrm{~S}$ & G & W \\
\hline N-TIMP2 ${ }_{14 \_11}$ & $\mathrm{~K}$ & I & $\mathrm{D}$ & $\mathrm{D}$ & G & $\mathrm{V}$ & $\mathrm{V}$ \\
\hline N-TIMP2 $14 \_12$ & Q & I & $\mathrm{D}$ & $\mathrm{F}$ & G & $\mathrm{E}$ & I \\
\hline N-TIMP2 $2_{14 \_17}$ & $\mathrm{D}$ & $\mathrm{L}$ & $\mathrm{S}$ & $\mathrm{D}$ & $\mathrm{S}$ & $\mathrm{S}$ & $\mathrm{F}$ \\
\hline N-TIMP2 ${ }_{14 \_18}$ & $\mathrm{~K}$ & $\mathrm{~L}$ & $\mathrm{~F}$ & $\mathrm{~F}$ & $\mathrm{~V}$ & $\mathrm{E}$ & $\mathrm{T}$ \\
\hline N-TIMP2 ${ }_{14 \_19}$ & $\mathrm{~K}$ & $\mathrm{~L}$ & $\mathrm{~L}$ & $\mathrm{D}$ & $\mathrm{A}$ & $\mathrm{V}$ & $\mathrm{Y}$ \\
\hline N-TIMP2 $2_{91}$ & $\mathrm{P}$ & $\mathrm{P}$ & W & $\mathrm{N}$ & I & M & $\mathrm{K}$ \\
\hline N-TIMP2 ${ }_{99}$ & $\mathrm{P}$ & $\mathrm{P}$ & W & I & I & M & $\mathrm{K}$ \\
\hline $\mathrm{N}-\mathrm{TIMP} 2_{913}$ & $\mathrm{P}$ & $\mathrm{P}$ & $\mathrm{W}$ & $\mathrm{N}$ & $\mathrm{V}$ & $\mathrm{K}$ & $\mathrm{K}$ \\
\hline
\end{tabular}

TIMP $2_{91}$ and N-TIMP $2_{913}$ inhibited MMP9 with $K i$ values of $0.78^{-} \pm 0.02 \mathrm{nM}$ and $1.2 \pm 0.007 \mathrm{nM}$, respectively, reflecting comparable binding towards MMP9 as towards $\mathrm{N}-\mathrm{TIMP} 2_{\mathrm{WT}}$. Nevertheless, these clones showed a dramatic decrease in affinity towards MMP14 ${ }_{\mathrm{CAT}}$, with $K i$ values of $240 \pm 31 \mathrm{nM}$ and $832 \pm 44 \mathrm{nM}$, respectively. As a result, the calculated specificities towards $\mathrm{MMP}_{\mathrm{CAT}}$ (i.e., the ratio between the fold change of the $K i$ to MMP9 ${ }_{\text {CAT }}$ to the fold change of the $K i$ to MMP14, relative to the same ratio obtained with $\mathrm{N}-\mathrm{TIMP} 2_{\mathrm{wT}}$ ) of $\mathrm{N}-\mathrm{TIMP} 2_{9}$ and $\mathrm{N}-\mathrm{TIMP} 2_{9}{ }_{13}$ were $\sim 30$ and $\sim 70$, respectively. To further evaluate target selectivity, the selective variants N-TIMP2 ${ }_{14}$ and N-TIMP2 $2_{913}$ were tested in a kinetic inhibition assay against two other MMP family members, i.e., $\mathrm{MMP}_{\mathrm{CAT}}$ (collagenase) and MMP10 ${ }_{\mathrm{CAT}}$ (stromelysin). The MMP14-selective variant N-TIMP2 ${ }_{14}{ }_{17}$ had the same affinity as N-TIMP $2_{\text {wT }}$ towards MMP1 and MMP10, with $K i$ values of $0.9 \pm 0.1 \mathrm{nM}$ and $3.2 \pm 0.46 \mathrm{nM}$, respectively (Table 3, Figure 3G,3H). Consequently, the values of the calculated specificity for binding of TIMP2 ${ }_{14}{ }_{17}$ to MMP $14_{\text {CAT }}$ over MMP1 $1_{\text {CAT }}$ and MMP10 ${ }_{\text {CAT }}$ were $21 \overline{2}$ and 154 , respectively. On the other hand, in comparison to $\mathrm{N}-\mathrm{TIMP} 2_{\mathrm{wT}}$, the MMP9-selective variant N-TIMP2 ${ }_{9}$ showed a decrease in affinity towards MMP1 $1_{\mathrm{CAT}}$ and

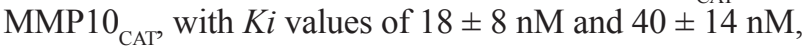
respectively (Table 3, Figure $3 \mathrm{G}, 3 \mathrm{H}$ ). The calculated specificity of N-TIMP2 $2_{913}$ to $\mathrm{MMP}{ }_{\mathrm{CAT}}$ over $\mathrm{MMP} 1_{\mathrm{CAT}}$ and MMP10 ${ }_{\mathrm{CAT}}$ was, therefore, 10- and 5-fold higher, respectively.

\section{N-TIMP2 variants selective to MMP14 inhibit MMP2 activation in U87MG cancer cells}

MMP2 is processed to its active form upon cleavage by MMP14. Active MMP2 in turn promotes invasion by and metastasis of different cancers $[69,70]$. Accordingly, inhibition of MMP14 was previously shown to inhibit the activation of MMP2 [71]. To examine whether our selective clones could selectively inhibit the activity of MMP14 in a cancer cell model, we performed a gelatin zymography assay with U87-malignant glioma (U87MG) cells, which naturally express high levels of MMP14, MMP9 and MMP2 [70, 72, 73]. U87MG cells were incubated in serum-free medium for $48 \mathrm{~h}$ in the presence or absence of the inhibitors. Thereafter, the media were collected and resolved by SDS-PAGE with $1 \%$ gelatin embedded in the gel, allowing for the inactive and active forms of MMP2 to be visualized (Figure 4A). N-TIMP2 ${ }_{\text {WT }}$ and the MMP14-selective inhibitors successfully reduced the amounts of active MMP2 (Figure 4), with 45\% inhibition being seen with N-TIMP $2_{\text {WT }}$ and N-TIMP $2_{14}$, and $50 \%$ inhibition being obtained with N-TIMP $2_{14} 18$. The selective MMP9-inhibiting variant N-TIMP $2_{9}{ }_{13}$ showed no inhibition of MMP14-induced MMP2 activation, consistent with its low affinity to MMP14.

\section{Selective MMP9 inhibitors inhibit the gelatinolytic activity of MMP9}

Many cancer cell lines express both MMP14 and MMP9 [74, 75]. To assess the specific effects of our selective inhibitors on each MMP, we utilized the MCF7 breast cancer cell line that is naturally MMP14- and MMP9-deficient $[76,77]$. First, we stably transfected the cells with a full-length MMP9 construct to generate MCF7-MMP9 cells. Since MMP9 is a secreted gelatinase, we confirmed its expression by gelatin zymograpy (Figure 5A, 5C). As expected, wild type MCF-7 cells that did not express MMP9 showed no such activity, whereas MCF-7-MMP9 cells exhibited gelatin degradation (Figure 5A, 5C, 5D). To address the selective inhibition of gelatin degradation by our N-TIMP2-specific MMP14 and MMP9 inhibitors, the supernatant of MCF-7MMP9 cells was resolved by SDS-PAGE using gelatinembedded gels and treated with $100 \mathrm{nM}$ of the inhibitors. The strongest inhibition of gelatin-degrading activity 
Table 2: Inhibition constants (Ki) of MMP14 and MMP9 with N-TIMP2 selective variants

\begin{tabular}{|c|c|c|c|c|c|}
\hline \multirow[b]{2}{*}{ Clone } & \multicolumn{2}{|c|}{$K i^{*}(n M)$} & \multicolumn{2}{|c|}{ Fold change of $K i^{* *}$} & \multirow[b]{2}{*}{$\begin{array}{l}\text { Specificity } \\
\text { shift }^{* * *}\end{array}$} \\
\hline & $\mathrm{MMP} 14_{\mathrm{CAT}}$ & MMP9 $_{\text {CAT }}$ & $\mathrm{MMP14}_{\mathrm{CAT}}$ & MMP9 $_{\mathrm{CAT}}$ & \\
\hline N-TIMP $2_{\mathrm{WT}}$ & $5 \pm 1$ & $0.5 \pm 0.04$ & & & \\
\hline N-TIMP2 ${ }_{14 \_17}$ & $0.03 \pm 0.003$ & $3.58 \pm 0.5$ & 170 & 0.14 & 1175 \\
\hline N-TIMP $2_{14 \_18}$ & $0.024 \pm 0.005$ & $1.25 \pm 0.2$ & 211 & 0.41 & 512 \\
\hline N-TIMP2 $2_{9 \_1}$ & $240 \pm 31$ & $0.78 \pm 0.02$ & 0.021 & 0.66 & 31 \\
\hline N-TIMP $2_{913}$ & $832 \pm 44$ & $1.2 \pm 0.007$ & 0.006 & 0.41 & 68 \\
\hline
\end{tabular}

${ }^{*} K_{i}$ values $(\mathrm{nM})$ of the purified variants were obtained by fitting the experimental data to Morrison's tight binding equation (Eq. 1).

*** Fold change of $K i$ reflects the ratio between the $K_{i}$ of N-TIMP $2_{\text {wT }}$ and the $K_{i}$ of an N-TIMP2 variant.

${ }^{* * *}$ For the MMP14-inhibiting clones N-TIMP2 ${ }_{14}{ }_{17}$ and N-TIMP2 ${ }_{14}{ }_{18}$, specificity shifts were calculated as the ratio between the fold improvement to $\mathrm{MMP}_{14_{\mathrm{CAT}}}$, as compared to $\mathrm{MMP}_{\mathrm{CAT}}$ (the specificity shift is defined as the fold change of $K_{i}$ for MMP14/fold change of $K i$ for MMP9). For the MMP9-inhibiting clones N-TIMP2 ${ }_{91}$ and N-TIMP2 ${ }_{9}$, specificity shifts were calculated as the ratio between the fold of improvement to MMP9 in comparison to MMP14 (the specificity shift is defined as the fold change of $K_{i}$ for MMP9/fold change of $K i$ for MMP14).

Table 3: Inhibition constants $\left(K_{i}\right)$ of $M M P 1_{C A T}$ and MMP10 ${ }_{\mathrm{CAT}}$ with N-TIMP2 selective variants

\begin{tabular}{|c|c|c|c|c|c|c|}
\hline \multirow[b]{2}{*}{ Clone } & \multicolumn{2}{|c|}{$K_{i}^{*}(n M)$} & \multicolumn{2}{|c|}{ Fold change of $K_{i}^{* *}$} & \multicolumn{2}{|c|}{ Specificity shift } \\
\hline & MMP1 $1_{\mathrm{CAT}}$ & MMP10 $_{\text {CAT }}$ & MMP1 $_{\mathrm{CAT}}$ & MMP10 $_{\mathrm{CAT}}$ & MMP1 $_{\mathrm{CAT}}$ & $\operatorname{MMP10}_{\mathrm{CAT}}$ \\
\hline N-TIMP2 $2_{\mathrm{WT}}$ & $0.7 \pm 0.1$ & $3.5 \pm 0.8$ & & & & \\
\hline N-TIMP2 ${ }_{14 \_17}$ & $0.92 \pm 0.15$ & $3.2 \pm 0.4$ & 0.8 & 1.1 & $212^{\#}$ & $154^{\#}$ \\
\hline N-TIMP $2_{913}$ & $18 \pm 8$ & $40 \pm 14$ & 0.04 & 0.08 & $10^{+}$ & $5^{+}$ \\
\hline
\end{tabular}

${ }^{*} K_{i}$ values $(\mathrm{nM})$ of the purified variants were obtained by fitting the experimental data to Morrison's tight binding equation (Eq. 1).

${ }^{* *}$ Fold change of $K i$ reflects the ratio between the $K_{i}$ of N-TIMP ${ }_{\text {WT }}$ and the $K_{i}$ of an N-TIMP2 variant.

\# For the MMP14-inhibiting clone N-TIMP2 ${ }_{14}$, specificity shifts were calculated as the ratio between the fold improvement to MMP14 ${ }_{\mathrm{CAT}}$, as compared to MMP1 $1_{\mathrm{CAT}}$ and MMP10 ${ }_{\mathrm{CAT}}$ (the specificity shift is defined as the fold change of $K_{i}$ for MMP14/fold change of $K i$ for MMPX, where X designates either MMP1 $1_{\mathrm{CAT}}$ or MMP10 ${ }_{\mathrm{CAT}}$ ).

${ }^{+}$For the MMP9-inhibiting clone N-TIMP2 ${ }_{913}$, specificity shifts were calculated as the ratio between the fold of improvement to $\mathrm{MMP}_{\mathrm{CAT}}$ in comparison to $\mathrm{MMP}_{\mathrm{CAT}}$ and MMP10 ${ }_{\mathrm{CAT}}$ (the specificity shift is defined as the fold change of $K_{i}$ for MMP9/fold change of $K i$ for MMPX, where X designates either MMP1 $1_{\mathrm{CAT}}$ or MMP10 ${ }_{\mathrm{CAT}}$ ).

$(\sim 86 \%)$ was obtained upon treatment with N-TIMP $2_{\text {WT }}$ (Figure 4B). The MMP9-selective N-TIMP2 $2_{9}$ and $\mathrm{N}-\mathrm{TIMP} 2_{9}{ }_{13}$ proteins caused $\sim 82 \%$ and $\sim 75 \%$ inhibition of gelatin degradation activity, respectively. This finding is consistent with the slightly higher affinity of N-TIMP $2_{\text {WT }}$ towards MMP9, as compared to the affinities of the two clones. Also as expected, the MMP14-binding clones did not cause inhibition of MMP9 gelatinolytic activity.

\section{Selective inhibition of MMP14- and MMP9- induced MCF-7 cell migration}

Wild type MCF-7 cells lack migratory abilities [78] due to a lack of MMP14 expression [77]. At the same time, stable expression of MMP14 in these cells induced migration and invasion [77]. Previous works also showed that induction of MMP9 expression increased the invasiveness of MCF-7 cells [79]. We performed trans-well migration assays for the purpose of exploring the effects of our selective inhibitors on the migration of MCF-7 cells stably expressing either MMP14 (Figure 5B) or MMP9. In the assay, wild type MCF-7 cells did not migrate through the membrane. In contrast, significant migration was observed with MCF-7-MMP14 and MCF7-MMP9 cells (Figure 6A-6C). Our N-TIMP2 variants could specifically inhibit the migration induced in MCF7-MMP14 and MCF-7-MMP9 cells by MMP14 or MMP9, respectively, in a dose-dependent manner (Figure 6 and Supplementary Figure 4). In the MMP14-expressing cells, N-TIMP $2_{\mathrm{WT}}$ and N-TIMP $2_{14}$ i7 inhibited migration by $30 \%$ and $38 \%$, respectively, while N-TIMP $2_{14} 18$ reduced migration by $\sim 50 \%$. As expected, both MMP9binding variants (N-TIMP2 $2_{9}$ and N-TIMP2 $\left.{ }_{9}{ }_{13}\right)$ did not inhibit MCF-7-MMP14 cell migration. The same trend was observed with MCF-7-MMP9 cells. The MMP14binding variants did not inhibit the migration of MCF-7- 
MMP9 cells, whereas treatment with the MMP9-selective inhibitors N-TIMP2 $2_{91}$ and N-TIMP2 ${ }_{9}{ }_{13}$ caused $\sim 30 \%$ inhibition (Figure 6D).

\section{DISCUSSION}

In this report, we described a new strategy for generating binding specificity in protein ligands through a combination of YSD and selective library screening against a target pair, each labeled with a different fluorophore. Employing the TIMP2/MMP system as the PPI of interest, we demonstrated how our strategy can be used to develop selective inhibitors for proteins that share high sequence homology and structural similarity in a rapid, singlestep and cost-effective manner. Several studies in which selective binders were obtained using different library screening and affinity maturation approaches have been described for both basic and applicative research. These include the development of the neurotensin receptor, a GPCR family member, to bind its neurotensin (NT) agonist but not the small molecule SR 48692 antagonist [80], Fc-conjugated cytotoxic T lymphocyte-associated protein 4 (CTLA4-Ig) engineered to selectively bind either CD86 [81] or CD80 [82], and cystine knot peptides with selective binding towards specific types of integrins $[34,83]$. These approaches, however, employed screens either against single targets or against a labeled desired target in the presence of other unlabeled undesired targets $[33,34,83]$. As such, these methods usually produced mutants that bind the desired target with high affinity yet which also exhibit higher affinity for other off targets [33, $81,82]$. For example, affinity maturation of the human Agouti-related protein (AgRP) against $\alpha_{\mathrm{v}} \beta_{3}$ integrin also resulted in high affinity to $\alpha_{\mathrm{v}} \beta_{5}$, and $\alpha_{5} \beta_{1}$ integrins [84]. Nevertheless, in those cases that yielded selective binders, as in the follow-up study where the same AgRP was evolved to specifically bind $\alpha_{\mathrm{IIb}} \beta_{3}$ integrin over $\alpha \mathrm{v} \beta_{3}$, $\alpha v \beta_{5}$ and $\alpha_{5} \beta_{1}[34]$, neither specificity switching variants
A

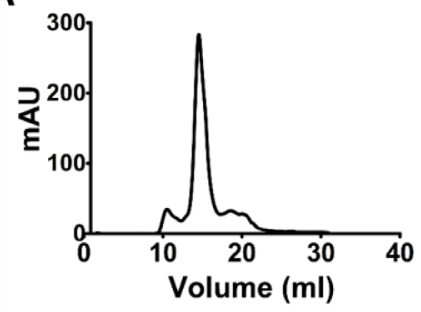

D

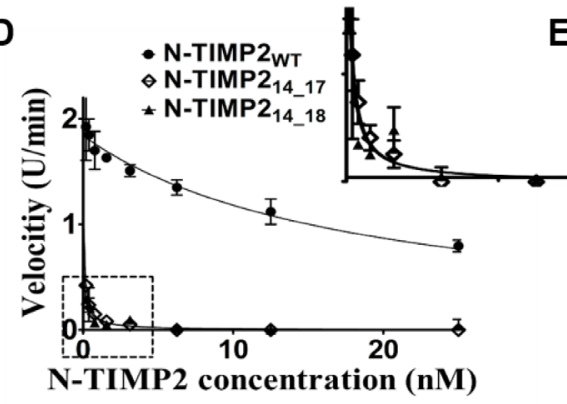

B

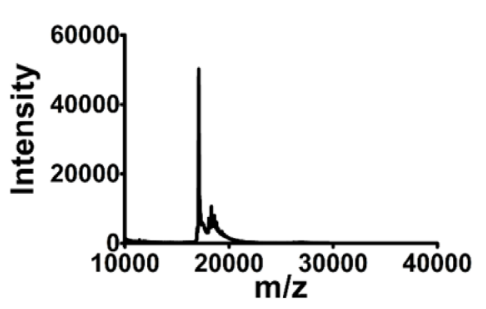

E

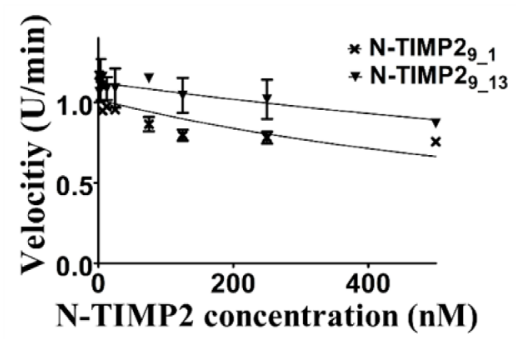

C

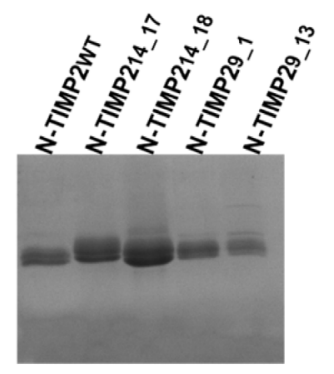

$\mathbf{F}$

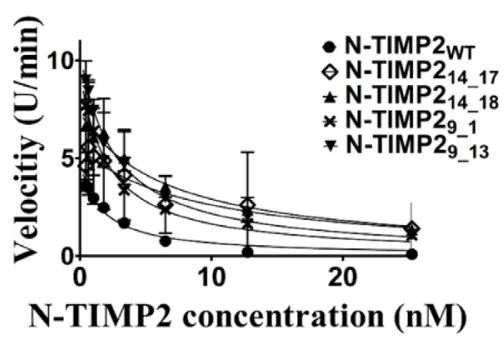

G

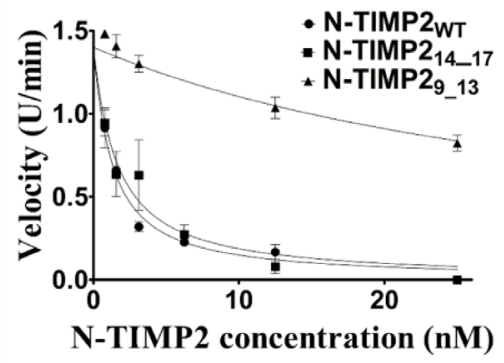

H

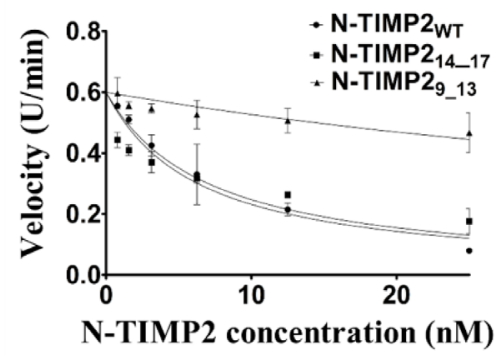

Figure 3: Purification of N-TIMP2 selective variants. (A) SEC (using Superdex75) analysis of clone N-TIMP2 ${ }_{14}{ }_{17}$. (B) Mass

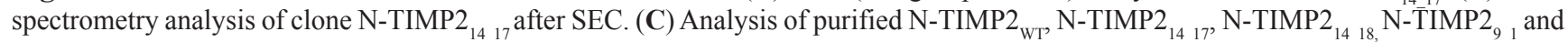
N-TIMP $2_{9 \_13}$ by $15 \%$ SDS-PAGE performed under reducing conditions. (D) MMP14 ${ }_{\mathrm{CAT}}$ inhibition by various concentrations of N-TIMP $2_{\text {WT }}$, N-TIMP2 $2_{14-17}^{-13}$ and N-TMP2 ${ }_{14 \_18}$. Cleavage of the fluorescent substrate was measured over time, with the velocity (slope) of the reaction as a function of inhibitor concentration being fitted to Morrison's equation to obtain the inhibition constant $K i$. (E) MMP14 ${ }_{\text {CAT }}$ inhibition by various concentrations of N-TIMP2 ${ }_{9-1}$ and N-TIMP2 $2_{913}$. (F) Inhibition of MMP9 ${ }_{\mathrm{CAT}}$ by N-TIMP2 $2_{\mathrm{WT}}$ and selective inhibitors. (G) Inhibition of MMP $1_{\mathrm{CAT}}$ by N-TIMP2 $2_{\mathrm{WT}}$ and the selective inhibitors. $(\mathbf{H})$ Inhibition of MMP10 ${ }_{\mathrm{CAT}}$ by N-TIMP2 ${ }_{\mathrm{WT}}$ and the selective inhibitors. 
A

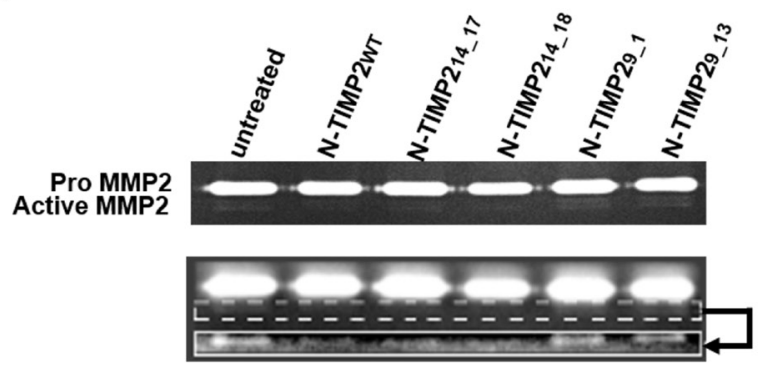

B

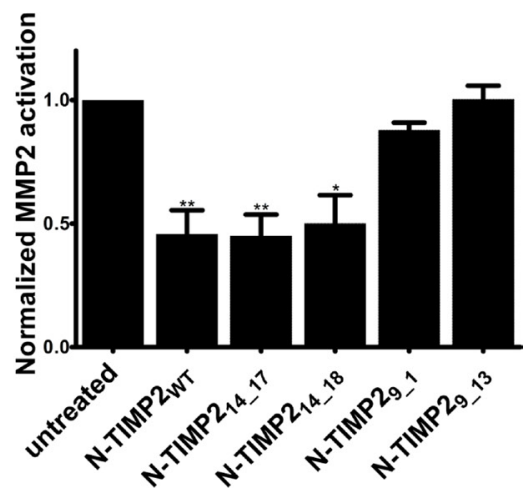

Figure 4: Inhibition of MMP2 activation by MMP14. (A) Representative results of gelatin zymography analysis of media collected from U87MG cells incubated with $100 \mathrm{nM}$ of the inhibitors for $48 \mathrm{~h}$ and resolved by SDS-PAGE. The bands in the top panel reflect inactive pro-MMP2, while the boxed region in the bottom panel contains bands that reflect active MMP2. The bottom panel in fact corresponds to the same gel used to generate the top panel, albeit after enhanced exposure and with increased sensitivity of detection. Specifically, to generate the lower panel, only the upper bright bands in gel were covered and a picture of the lower bands with 6-fold increased exposure and a 2-fold increase in sensitivity was taken. In addition, the contrast was increased. (B) Quantification of band intensity from the gel containing active MMP2, normalized to the intensities of bands from gels of control (untreated) cells. The experiment was repeated three times; means and standard error are given. ${ }^{*} P<0.05,{ }^{* *} P<0.01$, as determined by $t$ tests comparing the indicated condition versus the untreated control.

A

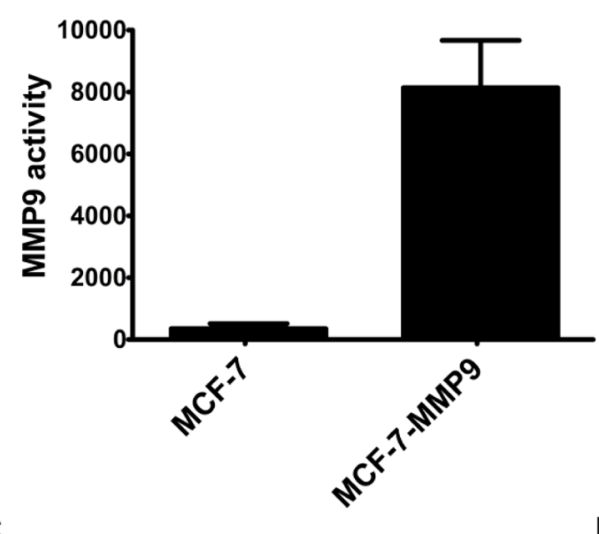

C

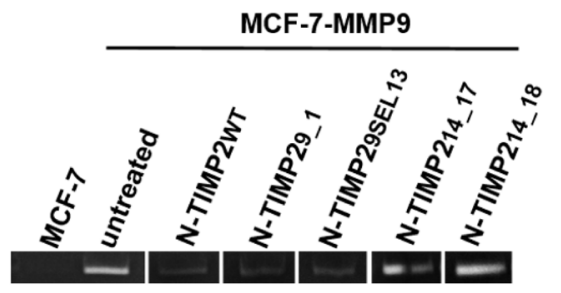

B
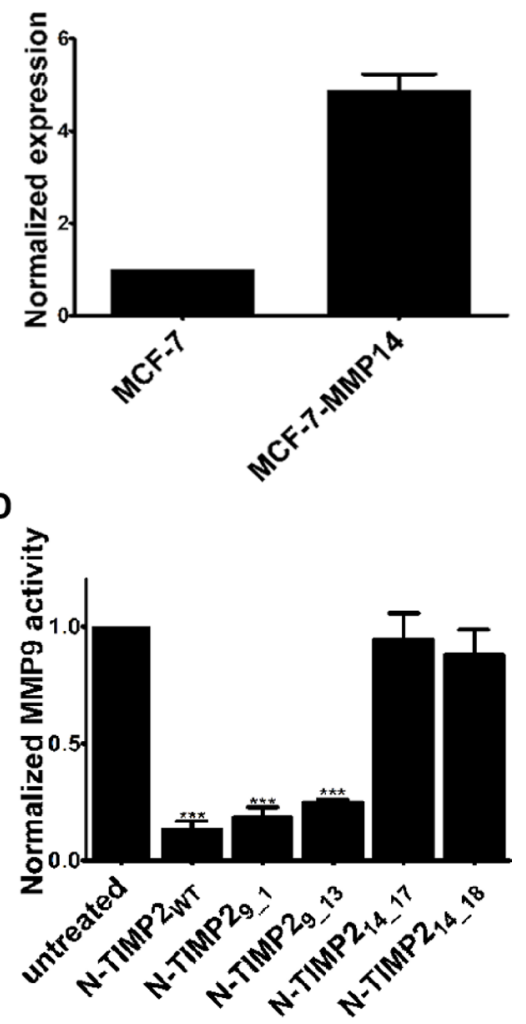

Figure 5: Gelatin degradation by MMP9 produced in MCF-7-MMP9 cells. (A) Band intensity quantification of gelatin zymography analysis of media collected from MCF-7 and MCF-7-MMP9 cells. Band intensities were quantified by ImageJ software. (B) Normalized expression of MMP14 in MCF-7 and MCF-7-MMP14 cells was confirmed by flow cytometry using rabbit anti-MMP14 antibodies and secondary goat anti-rabbit PE antibodies. (C) Representative results of gelatin zymography analysis of media collected from untransfected MCF-7-WT cells and MCF-7-MMP9 cells stably expressing MMP9 resolved in SDS-PAGE and treated with $100 \mathrm{nM}$ of the inhibitors. (D) Quantification of band intensity normalized to the intensity obtained with control (untreated) cells. All the the experiments were performed in triplicate; means and standard error are shown. In $\mathrm{D},{ }^{* * *} P<0.001$, as determined in a $t$ test comparing activity in the presence of the various inhibitors versus the untreated control. 
were identified nor was major biological characterization validating their specific binding provided [83, 85]. In the present study using our novel strategy, we developed specificity-switching variants of N-TIMP2 that function as selective MMP9 and MMP14 inhibitors, with the selective activity being confirmed by in vitro inhibition, cell-based gelatin zymography and cell-based migration experiments in cells that simultaneously express MMP9 and MMP14 or only one of these targets.

The MMP family represent an ideal group of targets to demonstrate our strategy because inhibiting MMPs is of clinical value, as both MMP9 and MMP14 are involved in cancer progression [41, 86]. Moreover, MMP9 is also involved in angiogenesis inhibition [49, 87], while MMP14 is involved in muscle [52] and bone development
[88]. We and others have previously used computational methods [3, 68, 89, 90] and X-ray crystallography $[60,66,89]$ to explore the structures of these proteases, in some cases identifying distinguishing features of individual MMPs that could be exploited for developing highly selective inhibitors $[3,60,68,91]$. Prior to the present, however, inhibitors capable of discriminating between MMPs had yet to be described.

N-TIMP2 attracted our interest as a scaffold for engineering selective MMP inhibitors due to the marked sequence diversity among TIMP family members (only $40-50 \%$ sequence identity), and given that all possess canonical binding interfaces that are highly tolerant to residue substitution or the incorporation of additional amino acids [3, 68, 92]. Because the sequences of
A

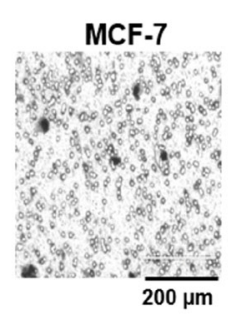

untreated

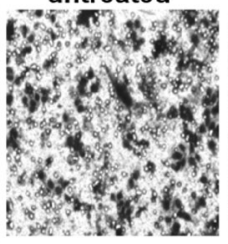

N-TIMP214_18

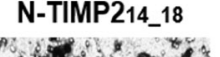

N-TIMP2WT N-TIMP214_17

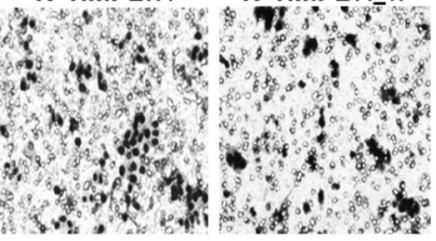

N-TIMP29_1 N-TIMP29_13

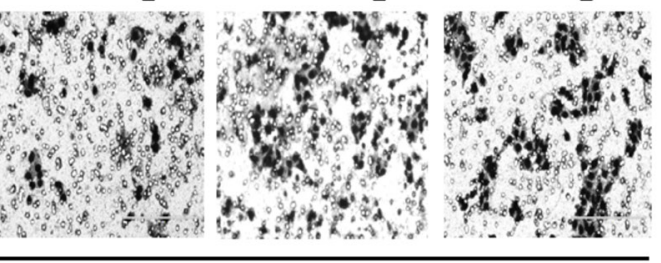

MCF-7-MMP14
B

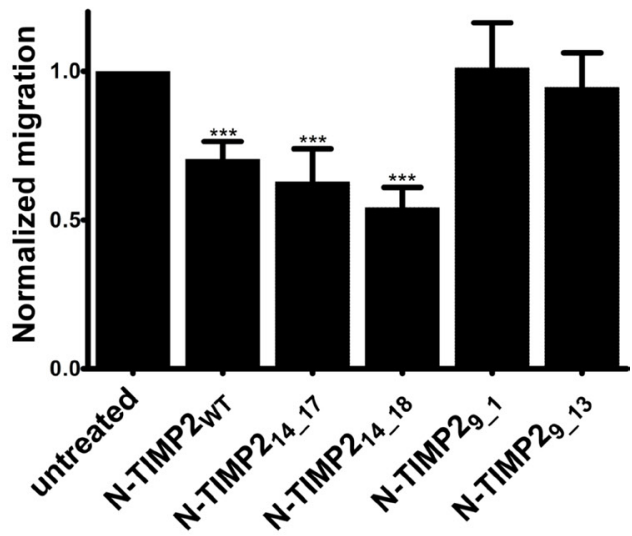

D

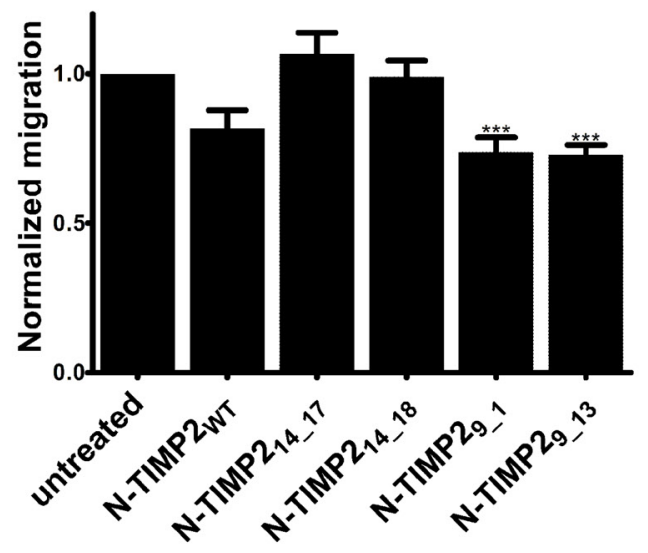

MCF-7-MMP9

Figure 6: Selective inhibition of MMP14- and MMP9-induced migration (A) Representative micrographs of migrating MCF-7 and MCF7-MMP14 cells in the presence or absence of $100 \mathrm{nM}$ of the N-TIMP2 inhibitors. The cells were stained with Dipp Kwik Differential Stain and visualized by light microscopy using a $\times 20$ magnification lens. (B) Calculated fold of migration of MCF-7-MMP14 cells. The cells were counted using ImageJ software and normalized to counts of untreated cells. (C) Representative micrographs of migrating MCF-7MMP9 cells in the presence or absence of $100 \mathrm{nM}$ of the N-TIMP2 inhibitors. The cells were visualized as in A. (D) Calculated fold of migration of MCF-7-MMP9 cells. The cells were counted as in B. The experiment was repeated three times; means and standard error are shown. ${ }^{* * *} P<0.001$, as determined by a $t$ test comparing inhibition in the presence of the various inhibitors versus the untreated control. 
the canonical binding interface largely determine the affinity and specificity of an inhibitor to its target [65, 93], exploiting N-TIMP2 as a scaffold offers a unique opportunity to optimize target affinity and selectivity without compromising stability [94]. In addition, the affinity of wild-type N-TIMP-2 (N-TIMP $2_{\text {WT }}$ ) to MMP9 ${ }_{\text {CAT }}$ and $\mathrm{MMP} 14_{\mathrm{CAT}}$, is comparable $\left(K_{\mathrm{i}}(\mathrm{M})=(0.5 \pm 0.04) \times\right.$ $10^{-9}$, and $(5 \pm 1) \times 10^{-9}$ for MMP9 ${ }_{\mathrm{CAT}}$ and MMP14 ${ }_{\mathrm{CAT}}$, respectively $[3,68])$. These features make N-TIMP $2_{\mathrm{WT}}$ an optimal model scaffold for engineering binding specificity. The lack of large differences in terms of specificity toward MMP9 and MMP14 is a good starting point for changing/ shifting relative specificity. At the same time, the slightly lower specificity of N-TIMP2 toward MMP14 makes it a good target for engineering and testing specificity switches.

As validation of the utility of our approach, we showed that the YSD affinities of the selected N-TIMP2 clones of MMP9 ${ }_{\mathrm{CAT}}$ and MMP14 ${ }_{\mathrm{CAT}}$ correlated well with the target-binding specificity of the purified protein variants in solution, as measured by competitive inhibition studies. For example, the YSD binding analysis predicted a 10 -fold specificity enhancement of N-TIMP $2_{9}$ binding MMP9 ${ }_{\mathrm{CAT}}$ over MMP14 ${ }_{\mathrm{CAT}}$, as compared with N-TIMP2 ${ }_{\mathrm{WT}}$, which was in qualitative agreement with the 30 -fold enhancement in the $K_{\mathrm{i}}$ values measured for the soluble proteins. Similar agreement between YSD binding analysis results and measured $K_{\mathrm{i}}$ values was reported for the mesotrypsin-binding triple mutant amyloid $\beta$-protein precursor inhibitor (APPI) recently developed in our group, which showed a greater affinity increase in the soluble form than in YSD experiments [95].

An important and novel finding reported here was that in our system, mutation-tolerant positions complied with the cold-spot definition, albeit for specificity (i.e., selective binding to a specific MMP) rather than for affinity (i.e., increased binding to that MMP). As shown by our YSD binding assays, all of the mutants that were sorted for selective $\mathrm{MMP}_{\mathrm{CAT}}$ binding did not exhibit improved affinity to MMP9 ${ }_{\mathrm{CAT}}$. Nonetheless, all showed improved MMP9 specificity (or MMP14 specificity, in the case of mutants sorted for selective MMP14 binding). Overall, 5-10-fold improved specificity, either for MMP9 over MMP14, were noted in our analysis for the YSD selective clones. These results are likely directly derived from our specificity maturation approach.

We also validated the specificity changes attained using selected purified soluble N-TIMP2 variants and in vitro and cell-based MMP inhibition experiments. We generated and purified soluble versions of the N-TIMP2 variants that conferred an improvement in specificity in terms of binding to MMP9 ${ }_{\mathrm{CAT}}$, as opposed to MMP14 ${ }_{\mathrm{CAT}}$. These variants include those mutants for which the YSD binding analysis predicted specificity improvement from one MMP to the other. In comparison to N-TIMP $2_{\mathrm{WT}}$ that showed 10-fold difference in binding to MMP9 ${ }_{\text {CAT }}$ vs MMP14 ${ }_{\text {CAT }}$, the best mutant (namely, N-TIMP2 ${ }_{913}$ ) assessed in our in vitro inhibition experiments exhibited 700-fold better affinity in favor of MMP9 $_{\mathrm{CAT}}$ over MMP14 ${ }_{\mathrm{CAT}}$. In addition, the improvement in affinity of the N-TIMP2 ${ }_{14-17}$ mutant to MMP14 over MMP9 corresponded to 120 - times enhanced affinity, reflecting a specificity switch from MMP9 to MMP14 that was also predicted in the YSD binding analysis.

In addition to the improved binding specificity of our selective mutants towards MMP9 ${ }_{\mathrm{CAT}}$ (or MMP14 ${ }_{\mathrm{CAT}}$ ) relative to the other protease when studied as purified proteins, biological activities of the inhibitors in cells also correlated to the binding specificity results. When tested for their ability to inhibit the gelatinolytic activity of MMP9, our MMP9-selective N-TIMP2 variants showed selective inhibition of MMP9 stably expressed by MCF-7MMP9 cells. The same effect was observed in a different experimental system in which cell migration/mobility, previously shown to be dependent on the expression of MMP9 and MMP14, of MCF-7 cells stably expressing MMP9 was measured [77, 79]. Inhibited mobility was caused by N-TIMP2 ${ }_{\text {WT }}$ and the specific MMP9-inhibiting $\mathrm{N}$-TIMP2 protein variants at $100 \mathrm{nM}$ concentrations, whereas no inhibition was observed with any of the MMP14-specific N-TIMP2 variants. The same selectivity in inhibition was also observed in mobility assays of MMP14-expressing cells, where the specific MMP14 inhibitors inhibited the MCF-7-MMP14 cell mobility, with clone N-TIMP2 ${ }_{14 \_18}$ causing the highest degree of inhibition, and with none of MMP9-selective N-TIMP2 variants inhibiting this mobility. Moreover, in U87-MG cells, MMP2 activation was inhibited by the selective MMP14 inhibitors but not by the MMP9 inhibitors, suggesting that only the MMP14 inhibitors bound to MMP14, the activity of which is needed for MMP2 activation.

Finally, analysis of the libraries after sorting was limited by the number of sequences that could be obtained from single colonies. Nonetheless, we judged it to be unnecessary to sequence additional clones, because the library size had decreased significantly by the fourth round of selection in the case of the selective/competitive screens. We felt that further sequencing would not have identified greater mutational diversity in the final sorting stages. Despite the relatively small number of sequence clones, the use of a focused library and degenerate codons at multiple mutation-tolerant positions in the N-TIMP2 ligand allowed for the incorporation of multiple mutations at these positions and enabled us to identify a combination of mutations in the N-TIMP2 sequence that improved the binding specificity of this ligand towards its targets. In addition, the use of a focused library covered a large portion of the theoretical mutational diversity and provided a comprehensive screen of the binding interface. However, generating the library by using a combination of site-specific saturation mutagenesis on the canonical 
N-TIMP2 interface, together with random mutations at other positions in the gene (using error-prone PCR, for example) could allow us in future to identify residues that are distant from the interaction site. These specificityimproving mutations may also be beneficial for designing targeted therapeutics for different types of cancer or other diseases, as they can potentially specifically inhibit a particular MMP so as to minimize toxic effects.

In summary, we have established a methodology integrating a combination of focused combinatorial methods for library design and an YSD technique for dual-labeled target selective library screening under competitive conditions and employed this approach for the design of selective MMP inhibitors. In future, this methodology can be applied to the design of other protease inhibitors with stronger affinity or greater functionality. In more general terms, this work offers a model for future design projects in which data regarding the contributions of single positions on binding affinity is available. Such positions can be mutated and successfully combined in a combinatorial manner, as shown here, with the use of the YSD setup to obtain mutants possessing additional desirable characteristics.

\section{MATERIALS AND METHODS}

\section{Selective screening of an N-TIMP2 focused library}

A focused N-TIMP2 library with random mutations at seven positions of the N-TIMP2 gene affecting residues in the binding interface $(4,35,38,68,71,97$, 99) (PDB:1BUV) [60] was purchased from GenScript (Piscataway, NJ). Briefly, the library was prepared using NNS (where $\mathrm{N}$ represents $\mathrm{A}, \mathrm{C}, \mathrm{T}$ or $\mathrm{G}$ nucleotides, and $S$ represents $C$ and $G$ ) degenerate codons that were used to mutate the above mentioned positions in the $\mathrm{N}-\mathrm{TIMP} 2_{\mathrm{WT}}$ gene. The library was expressed in the yeast surface display (YSD) system [96] using the pCHA vector introduced into Saccharomyces cerevisiae EBY100, as previously described, followed by expression enrichment [68]. A library size of $8 \times 10^{6}$ clones was confirmed by performing serial dilutions on selective SDCAA plates $(2 \%$ dextrose, $0.67 \%$ yeast nitrogen base, $0.5 \%$ bactocasamino acids, $1.47 \%$ sodium citrate, $0.429 \%$ citric acid monohydrate, $\mathrm{pH} 4.5,1.5 \%$ agar). For sorting, the yeast libraries were grown in expression-inducing SGCAA medium ( $2 \%$ galactose, $0.67 \%$ yeast nitrogen base, $0.5 \%$ Bacto casamino acids, $0.54 \% \mathrm{Na}_{2} \mathrm{HPO}_{4} \cdot \mathrm{H}_{2} \mathrm{O}$, $0.86 \% \mathrm{NaH}_{2} \mathrm{PO}_{4}$ ) at $30^{\circ} \mathrm{C}$ overnight. The cells, numbering ten times the library size (or $10^{6}$ at least), were collected and washed with a buffer containing $50 \mathrm{mM}$ Tris- $\mathrm{HCl}$, $\mathrm{pH} 7.5,100 \mathrm{mM} \mathrm{NaCl}, 5 \mathrm{mM} \mathrm{CaCl}_{2}$ and $1 \%$ bovine serum albumin. In the first selective sort, the library was incubated with both $1 \mu \mathrm{M} \mathrm{MMP14}{ }_{\mathrm{CAT}}$ conjugated to DyLight-488 and $50 \mathrm{nM} \mathrm{MMP}_{\mathrm{CAT}}$ conjugated to
DyLight 650 for $1 \mathrm{~h}$ at room temperature. The selective screen was performed on an iCyt Synergy FACS apparatus (Sony Biotechnology, San Jose, CA), and about 1\% of the bound populations were selected using polygonal gates. For subsequent screens, the following combinations of simultaneously applied MMP14 ${ }_{\mathrm{CAT}}$ and MMP9 ${ }_{\mathrm{CAT}}$ were used: for the selection of MMP14 ${ }_{\mathrm{CAT}}$-binders, $250 \mathrm{nM}$ $\mathrm{MMP} 14_{\mathrm{CAT}}$ and $100 \mathrm{nM} \mathrm{MMP}_{\mathrm{CAT}}$ were used in the

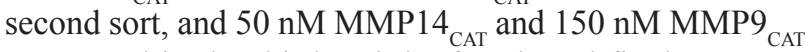
were used in the third and the fourth and final sort. For

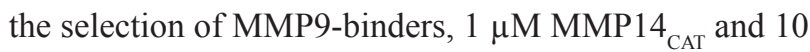
$\mathrm{nM} \mathrm{MMP}_{\mathrm{CAT}}$ were used in the second sort, while in the third and fourth screens, concentrations of $1 \mu \mathrm{M}$ and $1 \mathrm{nM}$ MMP9 $_{\text {CAT }}$ were applied, respectively. For flow cytometry analysis, the same labeling protocol as for the flow cytometry sorting was applied, using $10^{6}$ cells per analysis. The target concentrations used were $100 \mathrm{nM} \mathrm{MMP14}{ }_{\mathrm{CAT}}$ and $100 \mathrm{nM} \mathrm{MMP9}{ }_{\mathrm{CAT}}$ for the MMP14-specific clones and $1 \mu \mathrm{M} \mathrm{MMP} 14_{\mathrm{CAT}}$ and $10 \mathrm{nM} \mathrm{MMP}_{\mathrm{CAT}}$ for the MMP9specific clones. Flow cytometry analysis was performed on an Accuri C6 flow cytometer (BD Biosciences, San Jose, CA).

\section{DNA sequencing}

For sequencing the N-TIMP2 selective libraries after each round of sorting, the plasmid DNA was purified using a Zymoprep yeast plasmid miniprep I kit (ZymoResearch, Irvine, CA). The plasmid was then introduced into electrocompetent Escherichia coli cells which were grown on LB-agar plates containing ampicillin $(100 \mu \mathrm{g} / \mathrm{ml})$. Thereafter, about 20 colonies were transferred to liquid LB culture medium containing ampicillin and grown overnight at $37^{\circ} \mathrm{C}$. The plasmid was purified using a HiYield plasmid mini kit (RBC Bioscience, Taiwan) according to the manufacturer's protocol. The plasmids were sequenced by the Sanger sequencing method (Genetics Unit, NIBN), and the sequences were analyzed using Geneious R7 software (Biomatters, Auckland, New Zealand).

\section{Protein purification}

The portion of the human gene encoding the MMP14 catalytic domain (MMP14 ${ }_{\mathrm{CAT}}$, residues 112 292) was introduced into the pET3a vector that adds a C-terminal $6 \times \mathrm{His}$ tag and used to transform $E$. coli BL-21 (DE3) cells. Tagged MMP14 ${ }_{\text {CAT }}$ was purified as previously described $[65,97]$. The human MMP9 catalytic domain $\left(\mathrm{MMP}_{\mathrm{CAT}}\right.$ ) lacking the fibronectin-like domain (residues 107-215 and 391-443) was a generous gift from Irit Sagi (Weizmann Institute of Science, Rehovot, Israel). Purified MMP14 ${ }_{\mathrm{CAT}}$ and MMP9 ${ }_{\mathrm{CAT}}$ were labeled with DyLight-488 (Thermo Fisher, Waltham, MA) and DyLight-650 (Thermo Fisher), respectively, as previously described [68]. The catalytic activities of the labeled 
MMP14 ${ }_{\text {CAT }}$ and MMP9 ${ }_{\text {CAT }}$ enzymes were confirmed in an assay performed in TCNB buffer $(50 \mathrm{mM}$ Tris- $\mathrm{HCl}$, $\mathrm{pH} 7.5,100 \mathrm{mM} \mathrm{NaCl}, 5 \mathrm{mM} \mathrm{CaCl}_{2}$, and $0.05 \%$ Brij) with a final concentration of $15 \mu \mathrm{M}$ of the fluorogenic substrate Mca-Pro-Leu-Gly-Leu-Dpa-Ala-Arg- $\mathrm{NH}_{2} \cdot \mathrm{TFA}$, where Mca is (7-methoxycoumarin-4-yl)acetyl, Dpa is N-3-(2,4-dinitrophenyl)-L-2,3-diaminopropionyl and TFA is trifluoroacetic acid (Merck Millipore, Burlington, MA,). Fluorescence was monitored for $1 \mathrm{~h}$ using a Synergy 2 plate reader with 340/30 excitation and 400/30 emission filters (BioTek, Winooski, VT) at $37^{\circ} \mathrm{C}$. The catalytic domains of MMP1 and MMP10 (MMP1 $1_{\mathrm{CAT}}$ and MMP $10_{\mathrm{CAT}}$, respectively) were purified as previously described [66, 91].

$\mathrm{N}-\mathrm{TIMP} 2_{\mathrm{WT}}$ and the selective variants were produced in the $P$. pastoris X33 strain. The genes were first amplified with forward primers for N-TIMP $2_{\text {WT }}$ (5'-GGTATCTCTCGAGAAAAGATGCAGCTGCT CCCCG-3') and for the N-TIMP2 ${ }_{14}{ }_{1}, \mathrm{~N}, \mathrm{TIMP} 2_{14}{ }_{14}$, N-TIMP2 ${ }_{91}$ and N-TIMP2 ${ }_{913}$ variants (5'GGGTATCTCTCGAGAAAAGATGCAGCTGCGAC-3', 5'- GGGTATCTCTCGAGAAAAGATGCAGCTGCAA G-3', 5'- GGGTATCTCT CGAGAAAAGATGCAGCTGC CCC -3 ' respectively), and a common reverse primer (5'-GCTGGCGGCCGCCT CGCAGCCCATCTGGTA-3'). The amplified N-TIMP2 variants were digested with XhoI and NotI restriction enzymes (New England Biolabs, Ipswich, MA), as was the pPICZ $\alpha$ A vector that contains a zeocin resistance gene, the AOX1 promoter at the 5'-end of the insert and which introduces a $6 \times$ His tag at $\mathrm{C}$-terminus of the translated protein. The inserts and vector were ligated and the resulting plasmid was introduced into electro-competent E. coli cells. The transformed bacteria were plated on LB agar plates containing $50 \mu \mathrm{g} / \mathrm{ml}$ zeocin (Invitrogen, Grand Island, NY). The sequences of extracted plasmids from a few clones per each N-TIMP2 mutant were verified (Genetics Unit, NIBN). Then, $100 \mu \mathrm{g}$ of plasmid containing the correct sequence were linearized upon digestion with the SacI restriction enzyme (New England Biolabs). Plasmids containing the N-TIMP2 variants were transformed into electro-competent $P$. pastoris $\mathrm{X} 33$ according to the $\mathrm{pPICZ} \alpha$ protocol (Invitrogen). The transformed yeast were grown on YPDS plates ( $2 \%$ peptone, $1 \%$ yeast extract, $2 \% \mathrm{D}$-glucose, $1 \mathrm{M}$ sorbitol, $2 \%$ agar) for $72 \mathrm{~h}$ at $30^{\circ} \mathrm{C}$. For expression, several colonies encoding each of the N-TIMP2 variants were grown in $5 \mathrm{ml}$ liquid BMGY medium (2\% peptone, $1 \%$ yeast extract, $0.23 \% \mathrm{~K}_{2} \mathrm{H}\left(\mathrm{PO}_{4}\right), 1.1812 \% \mathrm{KH}_{2}\left(\mathrm{PO}_{4}\right)$, $1.34 \%$ yeast nitrogen base, $4 \times 10^{-5} \%$ biotin, $1 \%$ glycerol). After overnight growth at $30^{\circ} \mathrm{C}$, the cultures were grown in inductive $\mathrm{BMMY}$ medium ( $2 \%$ peptone, $1 \%$ yeast extract, $0.23 \% \mathrm{~K}_{2} \mathrm{H}\left(\mathrm{PO}_{4}\right), 1.1812 \% \mathrm{KH}_{2}\left(\mathrm{PO}_{4}\right), 1.34 \%$ yeast nitrogen base, $4 \times 10^{-5 \%}$ biotin, $0.5 \%$ methanol) for $72 \mathrm{~h}$ at $30^{\circ} \mathrm{C}$, with daily addition of $1 \%$ methanol. Over-expression of the secreted proteins was determined by western blot, using a 1:3000 dilution of mouse anti- $6 \times$ His primary antibodies (Abcam, Cambridge, UK), followed by a 1:5000 dilution of anti-mouse secondary antibodies conjugated to alkaline phosphatase (Jackson ImmunoResearch, West Grove, PA), and detection by incubation in $2 \mathrm{ml}$ of 5-bromo-4-chloro-3indolyl phosphate reagent (Sigma-Aldrich, St. Louis, MO). Large-scale production of the proteins was performed by growth of the N-TIMP2-expressing yeast clone exhibiting the highest amount of the desired protein for $72 \mathrm{~h}$ in BMMY medium, with $1 \%$ methanol added daily. During purification of the proteins, the yeast cell suspensions were centrifuged at $3800 \mathrm{~g}$ for $10 \mathrm{~min}$ and the supernatant was filtered, followed by addition of $500 \mathrm{mM} \mathrm{NaCl}$ and $10 \mathrm{mM}$ imidazole, $\mathrm{pH}$ 8.0. The supernatants were incubated for $1 \mathrm{~h}$ at $4^{\circ} \mathrm{C}$ and loaded onto nickel-nitrilotriacetic acid-Sepharose beads (Invitrogen), washed with $50 \mathrm{mM}$ Tris-HCl, pH 7.5, $100 \mathrm{mM}$ $\mathrm{NaCl}$, and $10 \mathrm{mM}$ imidazole, eluted with $20 \mathrm{ml}$ of $50 \mathrm{mM}$ Tris-HCl, pH 7.5, $100 \mathrm{mM} \mathrm{NaCl}, 300 \mathrm{mM}$ imidazole, and $5 \mathrm{mM} \mathrm{CaCl}_{2}$, and concentrated using a Vivaspin centrifugal concentrator with a 3-kDa cutoff (GE Healthcare Life Sciences, Pittsburgh, PA). The proteins were further purified using a Superdex 75 column with elution buffer $(50 \mathrm{mM}$ Tris- $\mathrm{HCl}, \mathrm{pH} 7.5,100 \mathrm{mM} \mathrm{NaCl}$ and $5 \mathrm{mM} \mathrm{CaCl}_{2}$ ) in an ÄKTA pure instrument (GE Healthcare Life Sciences) and separated by $15 \%$ SDS-PAGE under reducing conditions. Protein bands were visualized by staining with Instant Blue (CBS Scientific, Del Mar, CA). Protein samples were concentrated using a Vivaspin centrifugal concentrator with a 5-kDa cutoff (GE Healthcare Life Sciences) and subjected to mass spectrometry analysis (Ilse Katz Institute for Nanoscale Science and Technology, Ben-Gurion University). Protein concentrations were determined by UV-Vis absorbance at $280 \mathrm{~nm}$, using a NanoDrop Spectrophotometer (Thermo Scientific), with an extinction coefficient $\left(\varepsilon_{280}\right)$ of 13,500 $\mathrm{M}^{-1} \mathrm{~cm}^{-1}$ for N-TIMP2 ${ }_{\mathrm{wT}}$ and its variants. An average concentration of about $1 \mathrm{mg} / \mathrm{L}$ protein for all variants was measured.

\section{MMP inhibition studies}

N-TIMP $2_{\text {WT }}$ and its variants were tested for inhibitory activity against $0.0075 \mathrm{nM} \mathrm{MMP-14} 4_{\mathrm{CAT}}$ and $0.0075 \mathrm{nM}$ MMP-9 ${ }_{\mathrm{CAT}}$. For MMP14 ${ }_{\mathrm{CAT}}$ inhibition, 0.4$25 \mathrm{nM}$ of N-TIMP $2_{\text {WT }}$, N-TIMP $2_{14}$,, N-TIMP $2_{14 \_18}$ and $1.5-500 \mathrm{nM}$ of N-TIMP $2_{91}$ and N-TIMP $2_{913}$ were used. For inhibiting $\mathrm{MMP} 9_{\mathrm{CAT}}$ MMP1 $1_{\mathrm{CAT}}$ and $\mathrm{MMP} 10_{\mathrm{CAT}}$, $0.4-25 \mathrm{nM}$ of the inhibitors were used. The inhibition assays were performed in TCNB buffer $(50 \mathrm{mM}$ Tris$\mathrm{HCl}, \mathrm{pH} 7.5,100 \mathrm{mM} \mathrm{NaCl}, 5 \mathrm{mM} \mathrm{CaCl}_{2}$, and $0.05 \%$ Brij) for $1 \mathrm{~h}$ at $37^{\circ} \mathrm{C}$. Thereafter, the fluorogenic substrate Mca-Pro-Leu-Gly-Leu-Dpa-Ala-Arg- $\mathrm{NH}_{2} \cdot \mathrm{TFA}$, where Mca is (7-methoxycoumarin-4-yl)acetyl, Dpa is N-3(2,4-dinitrophenyl)-L-2,3-diaminopropionyl and TFA is trifluoroacetic acid (Merck Millipore, Burlington, MA,), was added at a final concentration of $15 \mu \mathrm{M}$ to the reaction, and fluorescence was monitored using a Synergy 2 plate reader with 340/30 excitation and 400/30 emission filters (BioTek, Winooski, VT) at $37^{\circ} \mathrm{C}$. Reactions were 
followed spectroscopically for $60 \mathrm{~min}$, and initial rates were determined from the linear portion of the increase in fluorescence signal caused by cleavage of the fluorescent substrate. Data were globally fitted by multiple regression to Morrison's tight binding inhibition equation (see Eq. 1) using Prism version 5.00 for Windows (GraphPad, La Jolla, CA). $K_{i}$ values were calculated by plotting the initial velocities against different concentrations of the inhibitors. Reported inhibition constants represent average values obtained from three independent experiments. Calculations were performed using $K_{m}$ values of $9.5 \pm 2.5$ $\mu \mathrm{M}$ for $\mathrm{MMP} 14_{\mathrm{CAT}}$ and $5.5 \pm 1.8 \mu \mathrm{M}$ for $\mathrm{MMP} 9_{\mathrm{CAT}}$, as determined from at least three Michaelis-Menten kinetic experiments performed in our laboratory.

(Eq.1)

$\frac{V_{i}}{V_{0}}=1-\frac{\left([E]+[I]+K_{i}^{a p p}\right)-\sqrt{\left([E]+[I]+K_{i}^{a p p}\right)^{2}-4[E][I]}}{2[E]}$

where $\mathrm{V}_{\mathrm{i}}$ is enzyme velocity in the presence of inhibitor, $\mathrm{V}_{0}$ is enzyme velocity in the absence of inhibitor, $\mathrm{E}$ is enzyme concentration, I is inhibitor concentration, $\mathrm{S}$ is substrate concentration, $\mathrm{K}_{\mathrm{m}}$ is the Michaelis-Menten constant; and $K_{i}^{\text {app }}$ is the apparent inhibition constant, given by: $K_{i}^{a p p}=K_{i}\left(1+\frac{[S]}{K_{m}}\right.$

\section{Cell culture}

MCF-7 human breast cancer cell line (a generous gift from Dan Levy, Ben-Gurion University) and U-87MG cells (American Type Culture Collection, Manassas, VA) were maintained in Dulbecco's modified Eagle's medium (DMEM; Biological Industries Beit-Haemek, Israel) supplemented with $10 \%$ fetal bovine serum (Thermo Fisher), 1\% l-glutamine (Biological Industries) and 1\% penicillin/streptomycin (Biological Industries).

\section{Stable cell line generation}

For generating stable MCF-7 cells expressing either MMP14 or MMP9, MCF-7 cells were seeded at a density of $10^{5}$ and incubated for $24 \mathrm{~h}$. The cells were then transfected with either plasmid pCMV MMP14 or plasmid pCMV MMP9 (Sino Biological, Beijing China) using Lipofectamin 3000 (Thermo Fisher) according to the manufacturer's instructions. Forty-eight h posttransfection, the cells were treated with $150 \mu \mathrm{g} / \mathrm{ml}$ of hygromycin (Thermo Fisher) followed by an incubation of 4 weeks. For assessing the expression of MMP14, MCF7 and MCF7-MMP14 cells were incubated for 1 $\mathrm{h}$ at room temperature with monoclonal anti-MMP14 rabbit antibodies (Abgent, San Diego, CA) following washing. The cells were then incubated for $30 \mathrm{~min}$ with secondary PE-conjugated goat-anti-rabbit antibodies
(Abcam) and analyzed on an Accuri C6 flow cytometer (BD Biosciences).

\section{Gelatinase zymography assay}

To test inhibition of endogenous MMP2 activation, a gelatin zymography assay was performed. U87MG cells $\left(2 \times 10^{4}\right)$ were grown for $48 \mathrm{~h}$ in serum-free DMEM in the presence or absence of $100 \mathrm{nM}$ of the protein inhibitors. The supernatants were collected and resolved by $7 \%$ SDSPAGE in the presence of $1 \%$ embedded gelatin (Sigma). The gel was rinsed for $1 \mathrm{~h}$ with gentle agitation in $2.5 \%$ Triton X-100 (Thermo Fisher) at room temperature and incubated overnight in $50 \mathrm{mM}$ Tris- $\mathrm{HCl}, \mathrm{pH} 7.5,10 \mathrm{mM}$ $\mathrm{CaCl}_{2}$ and $100 \mathrm{mM} \mathrm{NaCl}$ at $37^{\circ} \mathrm{C}$.

To examine inhibition of MMP9 activity by the N-TIMP2-based selective variants, $2 \times 10^{4}$ MCF-7MMP9 cells were grown in serum-free DMEM for 24 h. The supernatants were collected and resolved by $8 \%$ SDS-PAGE in the presence of $1 \%$ embedded gelatin. Afterwards, the gels were rinsed for $1 \mathrm{~h}$ with gentle agitation in $2.5 \%$ Triton $\mathrm{X}-100$ at room temperature and incubated overnight with $100 \mathrm{nM}$ of the N-TIMP2 inhibitors in $50 \mathrm{mM}$ Tris- $\mathrm{HCl}, \mathrm{pH} 7.5,10 \mathrm{mM} \mathrm{CaCl}_{2}$ and $100 \mathrm{mM} \mathrm{NaCl}$ at $37^{\circ} \mathrm{C}$. After incubation, the gels were stained with Simply-Blue SafeStain (Thermo Fisher), and gelatinolytic activity was visualized as clear bands. The signals obtained were quantified using ImageJ software. Validation of MMP9 expression in MCF-7 and MCF-7MMP9 cells was performed by the same method.

\section{Trans-well migration assays}

Trans-well migration assays were performed using ThinCert 24-well inserts (Greiner Bio-One, Kremsmünster, Austria). The bottom part of each insert was filled with DMEM supplemented with $10 \%$ fetal bovine serum. The upper compartment was filled with $200 \mu \mathrm{l}$ of MCF7, MCF7-MMP14 or MCF7-MMP9 cells $\left(2 \times 10^{4}\right)$ in the presence or absence of the inhibitors at concentrations of 250,100, 50 and $10 \mathrm{nM}$. The cells were incubated for $24 \mathrm{~h}$ at $37^{\circ} \mathrm{C}$. Thereafter, cells that had migrated were fixed, stained using a Dipp Kwik Differential Stain Kit (American Mastertech Scientific, Lodi, CA) and counted using an EVOS FL Cell Imaging System (Thermo Fisher) at $20 \times$ magnification. The experiment was performed in triplicate, with 10 fields being counted for each sample.

\section{Data analysis and statistics}

All experiments were performed in triplicate. The data was analyzed using GraphPad Prism version 5.00 for Windows. Statistical significance was determined by column statistics and $t$ test analysis. A $P$ value $<0.05$ was considered statistically significant. 


\section{Abbreviations}

FACS: fluorescence-activated cell sorting; FITC: fluorescein isothiocyanate; MFI: mean fluorescence intensity; MMP: matrix metalloprotease; PE: phycoerythrin; PPI: protein-protein interaction; RU: response unit; SDS-PAGE: sodium dodecyl sulfate polyacrylamide gel electrophoresis; SEC: size-exclusion chromatography; TIMP: tissue inhibitor of matrix metalloproteases; YSD: yeast surface display.

\section{Author contributions}

V.A. and N.P. designed the research, V.A. performed the research, E.S.R contributed proteins, V.A. and N.P. analyzed the data, and V.A. and N.P. wrote the paper. All authors edited the manuscript and approved the final version.

\section{ACKNOWLEDGMENTS}

The authors thank Dr. Alon Zilka for his technical assistance. FACS experiments were performed at the NIBN proteomics unit.

\section{CONFLICTS OF INTEREST}

The authors declare that they have no conflict of interest with respect to publication of this paper.

\section{FUNDING}

This work was supported by the European Research Council "Ideas program" ERC-2013-StG (contract grant number: 336041) and the Israel Science Foundation (grant number 615/14) to Niv Papo.

\section{REFERENCES}

1. Aizner Y, Sharabi O, Shirian J, Dakwar GR, Risman M, Avraham O, Shifman J. Mapping of the binding landscape for a picomolar protein-protein complex through computation and experiment. Structure. 2014; 22:636-45.

2. Gfeller D, Butty F, Wierzbicka M, Verschueren E, Vanhee P, Huang H, Ernst A, Dar N, Stagljar I, Serrano L, Sidhu SS, Bader GD, Kim PM. The multiple-specificity landscape of modular peptide recognition domains. Mol Syst Biol. 2011; 7:484.

3. Sharabi O, Shirian J, Grossman M, Lebendiker M, Sagi I, Shifman J. Affinity- and specificity-enhancing mutations are frequent in multispecific interactions between TIMP2 and MMPs. PLoS One. 2014; 9:e93712.

4. Fowler DM, Fields S. Deep mutational scanning: a new style of protein science. Nat Methods. 2014; 11:801-07.
5. Fowler DM, Stephany JJ, Fields S. Measuring the activity of protein variants on a large scale using deep mutational scanning. Nat Protoc. 2014; 9:2267-84.

6. Kowalsky CA, Klesmith JR, Stapleton JA, Kelly V, Reichkitzer N, Whitehead TA. High-Resolution Sequence-Function Mapping of Full-Length Proteins. PloS One. 2015; 10: e0118193.

7. Whitehead TA, Chevalier A, Song Y, Dreyfus C, Fleishman SJ, De Mattos C, Myers CA, Kamisetty H, Blair P, Wilson IA, Baker D. Optimization of affinity, specificity and function of designed influenza inhibitors using deep sequencing. Nat Biotechnol. 2012; 30:543-48.

8. Kortemme T, Joachimiak LA, Bullock AN, Schuler AD, Stoddard BL, Baker D. Computational redesign of proteinprotein interaction specificity. Nat Struct Mol Biol. 2004; 11:371-79.

9. Sharabi O, Shirian J, Shifman JM. Predicting affinityand specificity-enhancing mutations at protein-protein interfaces. Biochem Soc Trans. 2013; 41:1166-69.

10. Grigoryan G, Reinke AW, Keating AE. Design of proteininteraction specificity gives selective bZIP-binding peptides. Nature. 2009; 458:859-64.

11. Skerker JM, Perchuk BS, Siryaporn A, Lubin EA, Ashenberg O, Goulian M, Laub MT. Rewiring the specificity of two-component signal transduction systems. Cell. 2008; 133:1043-54.

12. Boyken SE, Chen Z, Groves B, Langan RA, Oberdorfer G, Ford A, Gilmore JM, Xu C, DiMaio F, Pereira JH, Sankaran B, Seelig G, Zwart PH, Baker D. De novo design of protein homo-oligomers with modular hydrogen bond networkmediated specificity. Science. 2016; 352:680-87.

13. Zheng F, Grigoryan G. Simplifying the Design of ProteinPeptide Interaction Specificity with Sequence-Based Representations of Atomistic Models. Methods Mol Biol. 2017; 1561:189-200.

14. Crooks RO, Baxter D, Panek AS, Lubben AT, Mason JM. Deriving Heterospecific Self-Assembling Protein-Protein Interactions Using a Computational Interactome Screen. J Mol Biol. 2016; 428:385-98.

15. Obarska-Kosinska A, Iacoangeli A, Lepore R, Tramontano A. PepComposer: computational design of peptides binding to a given protein surface. Nucleic Acids Res. 2016; 44:W522-W8.

16. Ley K, Rivera-Nieves J, Sandborn WJ, Shattil S. Integrinbased therapeutics: biological basis, clinical use and new drugs. Nat Rev Drug Discov. 2016; 15:173-83.

17. Leow CC, Coffman $\mathrm{K}$, Inigo I, Breen S, Czapiga M, Soukharev S, Gingles N, Peterson N, Fazenbaker C, Woods R, Jallal B, Ricketts SA, Lavallee T, et al. MEDI3617, a human anti-angiopoietin 2 monoclonal antibody, inhibits angiogenesis and tumor growth in human tumor xenograft models. Int J Oncol. 2012; 40:1321-30. 
18. Boekhout AH, Beijnen JH, Schellens JH. Trastuzumab. Oncologist. 2011; 16:800-10.

19. Feagan BG, Sandborn WJ, D’Haens G, Panés J, Kaser A, Ferrante M, Louis E, Franchimont D, Dewit O, Seidler U, Kim KJ, Neurath MF, Schreiber S, et al. Induction therapy with the selective interleukin-23 inhibitor risankizumab in patients with moderate-to-severe Crohn's disease: a randomised, double-blind, placebo-controlled phase 2 study. Lancet. 2017; 389:1699-709.

20. Havranek JJ, Harbury PB. Automated design of specificity in molecular recognition. Nat Struct Biol. 2003; 10:45-52.

21. Kaschner M, Schillinger O, Fettweiss T, Nutschel C, Krause F, Fulton A, Strodel B, Stadler A, Jaeger KE, Krauss U. A combination of mutational and computational scanning guides the design of an artificial ligand-binding controlled lipase. Sci Rep. 2017; 7:42592.

22. Fischer A, Seitz T, Lochner A, Sterner R, Merkl R, Bocola M. A fast and precise approach for computational saturation mutagenesis and its experimental validation by using an artificial $(\beta \alpha) 8$-barrel protein. Chembiochem. 2011; 12:1544-50.

23. Erijman A, Rosenthal E, Shifman JM. How structure defines affinity in protein-protein interactions. PLoS One. 2014; 9:e110085.

24. Rosenfeld L, Heyne M, Shifman JM, Papo N. Protein Engineering by Combined Computational and In Vitro Evolution Approaches. Trends Biochem Sci. 2016; 41:421-33.

25. Fleming PJ, Rose GD. Do all backbone polar groups in proteins form hydrogen bonds? Protein Sci. 2005; 14:1911-7.

26. Boder ET, Midelfort KS, Wittrup KD. Directed evolution of antibody fragments with monovalent femtomolar antigen-binding affinity. Proc Natl Acad Sci U S A. 2000; 97:10701-05.

27. Boder ET, Wittrup KD. Yeast surface display for screening combinatorial polypeptide libraries. Nat Biotechnol. 1997; 15:553-57.

28. Graff CP, Chester K, Begent R, Wittrup KD. Directed evolution of an anti-carcinoembryonic antigen $\mathrm{scFv}$ with a 4-day monovalent dissociation half-time at 37 degrees $\mathrm{C}$. Protein Eng Des Sel. 2004; 17:293-304.

29. Kieke MC, Shusta EV, Boder ET, Teyton L, Wittrup KD, Kranz DM. Selection of functional T cell receptor mutants from a yeast surface-display library. Proc Natl Acad Sci U S A. 1999; 96:5651-56.

30. Kim YS, Bhandari R, Cochran JR, Kuriyan J, Wittrup KD. Directed evolution of the epidermal growth factor receptor extracellular domain for expression in yeast. Proteins. 2006; 62:1026-35.

31. Shusta EV, Holler PD, Kieke MC, Kranz DM, Wittrup KD. Directed evolution of a stable scaffold for T-cell receptor engineering. Nat Biotechnol. 2000; 18:754-59.

32. Puri V, Streaker E, Prabakaran P, Zhu Z, Dimitrov DS. Highly efficient selection of epitope specific antibody through competitive yeast display library sorting. MAbs. 2013; 5:533-9.

33. Dutta S, Gullá S, Chen TS, Fire E, Grant RA, Keating AE. Determinants of $\mathrm{BH} 3$ binding specificity for $\mathrm{Mcl}-1$ versus Bcl-xL. J Mol Biol. 2010; 398:747-62.

34. Silverman AP, Kariolis MS, Cochran JR. Cystine-knot peptides engineered with specificities for $\alpha(\mathrm{IIb}) \beta(3)$ or $\alpha(\mathrm{IIb}) \beta(3)$ and $\alpha(\mathrm{v}) \beta(3)$ integrins are potent inhibitors of platelet aggregation. J Mol Recognit. 2011; 24:127-35.

35. Levin AM, Bates DL, Ring AM, Krieg C, Lin JT, Su L, Moraga I, Raeber ME, Bowman GR, Novick P, Pande VS, Fathman CG, Boyman O, Garcia KC. Exploiting a natural conformational switch to engineer an interleukin-2 'superkine'. Nature. 2012; 484:529-33.

36. Szwajkajzer D, Carey J. Molecular and biological constraints on ligand-binding affinity and specificity. Biopolymers. 1997; 44:181-98.

37. Bessette PH, Rice JJ, Daugherty PS. Rapid isolation of high-affinity protein binding peptides using bacterial display. Protein Eng Des Sel. 2004; 17:731-39.

38. Cui N, Hu M, Khalil RA. Biochemical and Biological Attributes of Matrix Metalloproteinases. Prog Mol Biol Transl Sci. 2017; 147:1-73.

39. Liu H, Kato Y, Erzinger SA, Kiriakova GM, Qian Y, Palmieri D, Steeg PS, Price JE. The role of MMP-1 in breast cancer growth and metastasis to the brain in a xenograft model. BMC Cancer. 2012; 12:583.

40. Pahwa S, Stawikowski MJ, Fields GB. Monitoring and Inhibiting MT1-MMP during Cancer Initiation and Progression. Cancers (Basel). 2014; 6:416-35.

41. Mook OR, Frederiks WM, Van Noorden CJ. The role of gelatinases in colorectal cancer progression and metastasis. Biochim Biophys Acta. 2004; 1705:69-89.

42. Folgueras AR, Pendas AM, Sanchez LM, Lopez-Otin C. Matrix metalloproteinases in cancer: from new functions to improved inhibition strategies. Int J Dev Biol. 2004; 48:411-24.

43. Ma XJ, Dahiya S, Richardson E, Erlander M, Sgroi DC. Gene expression profiling of the tumor microenvironment during breast cancer progression. Breast Cancer Res. 2009; 11:R7.

44. Têtu B, Brisson J, Wang CS, Lapointe H, Beaudry G, Blanchette C, Trudel D. The influence of MMP-14, TIMP-2 and MMP-2 expression on breast cancer prognosis. Breast Cancer Res. 2006; 8:R28.

45. Holmbeck K, Bianco P, Caterina J, Yamada S, Kromer M, Kuznetsov SA, Mankani M, Robey PG, Poole AR, Pidoux I, Ward JM, Birkedal-Hansen H. MT1-MMP-deficient mice develop dwarfism, osteopenia, arthritis, and connective tissue disease due to inadequate collagen turnover. Cell. 1999; 99:81-92.

46. Zhou Z, Apte SS, Soininen R, Cao R, Baaklini GY, Rauser RW, Wang J, Cao Y, Tryggvason K. Impaired endochondral ossification and angiogenesis in mice deficient in 
membrane-type matrix metalloproteinase I. Proc Natl Acad Sci U S A. 2000; 97:4052-57.

47. Pellikainen JM, Ropponen KM, Kataja VV, Kellokoski JK, Eskelinen MJ, Kosma VM. Expression of matrix metalloproteinase (MMP)-2 and MMP-9 in breast cancer with a special reference to activator protein-2, HER2, and prognosis. Clin Cancer Res. 2004; 10:7621-28.

48. Bendrik C, Robertson J, Gauldie J, Dabrosin C. Gene transfer of matrix metalloproteinase-9 induces tumor regression of breast cancer in vivo. Cancer Res. 2008; 68:3405-12.

49. Bendrik C, Karlsson L, Dabrosin C. Increased endostatin generation and decreased angiogenesis via MMP-9 by tamoxifen in hormone dependent ovarian cancer. Cancer Lett. 2010; 292:32-40.

50. Shchors K, Nozawa H, Xu J, Rostker F, Swigart-Brown L, Evan G, Hanahan D. Increased invasiveness of MMP-9deficient tumors in two mouse models of neuroendocrine tumorigenesis. Oncogene. 2013; 32:502-13.

51. Coussens LM, Tinkle CL, Hanahan D, Werb Z. MMP-9 supplied by bone marrow-derived cells contributes to skin carcinogenesis. Cell. 2000; 103:481-90.

52. Snyman C, Niesler CU. MMP-14 in skeletal muscle repair. J Muscle Res Cell Motil. 2015; 36:215-25.

53. Liang HP, Xu J, Xue M, Jackson C. Matrix metalloproteinases in bone development and pathology: current knowledge and potential clinical utility. Metalloproteinases Med. 2016; 3:93-102.

54. Reinhard SM, Razak K, Ethell IM. A delicate balance: role of MMP-9 in brain development and pathophysiology of neurodevelopmental disorders. Front Cell Neurosci. 2015; 9:280.

55. Overall CM, Kleifeld O. Tumour microenvironment opinion: validating matrix metalloproteinases as drug targets and anti-targets for cancer therapy. Nat Rev Cancer. 2006; 6:227-39.

56. López-Otín C, Matrisian LM. Emerging roles of proteases in tumour suppression. Nat Rev Cancer. 2007; 7:800-08.

57. Brinckerhoff CE, Matrisian LM. Matrix metalloproteinases: a tail of a frog that became a prince. Nat Rev Mol Cell Biol. 2002; 3:207-14.

58. Pirard B. Insight into the structural determinants for selective inhibition of matrix metalloproteinases. Drug Discov Today. 2007; 12:640-46.

59. Rowsell S, Hawtin P, Minshull CA, Jepson H, Brockbank SM, Barratt DG, Slater AM, McPheat WL, Waterson D, Henney AM, Pauptit RA. Crystal structure of human MMP9 in complex with a reverse hydroxamate inhibitor. J Mol Biol. 2002; 319:173-81.

60. Fernandez-Catalan C, Bode W, Huber R, Turk D, Calvete JJ, Lichte A, Tschesche H, Maskos K. Crystal structure of the complex formed by the membrane type 1-matrix metalloproteinase with the tissue inhibitor of metalloproteinases-2, the soluble progelatinase A receptor. EMBO J. 1998; 17:5238-48.

61. Gomis-Rüth FX, Maskos K, Betz M, Bergner A, Huber R, Suzuki K, Yoshida N, Nagase H, Brew K, Bourenkov GP,
Bartunik H, Bode W. Mechanism of inhibition of the human matrix metalloproteinase stromelysin-1 by TIMP-1. Nature. 1997; 389:77-81.

62. Maskos K, Lang R, Tschesche H, Bode W. Flexibility and variability of TIMP binding: X-ray structure of the complex between collagenase-3/MMP-13 and TIMP-2. J Mol Biol. 2007; 366:1222-31.

63. Wisniewska M, Goettig P, Maskos K, Belouski E, Winters D, Hecht R, Black R, Bode W. Structural determinants of the ADAM inhibition by TIMP-3: crystal structure of the TACE-N-TIMP-3 complex. J Mol Biol. 2008; 381:1307-19.

64. Iyer S, Wei S, Brew K, Acharya KR. Crystal structure of the catalytic domain of matrix metalloproteinase- 1 in complex with the inhibitory domain of tissue inhibitor of metalloproteinase-1. J Biol Chem. 2007; 282:364-71.

65. Grossman M, Tworowski D, Dym O, Lee MH, Levy Y, Murphy G, Sagi I. The intrinsic protein flexibility of endogenous protease inhibitor TIMP-1 controls its binding interface and affects its function. Biochemistry. 2010; 49:6184-92.

66. Batra J, Soares AS, Mehner C, Radisky ES. Matrix metalloproteinase-10/TIMP-2 structure and analyses define conserved core interactions and diverse exosite interactions in MMP/TIMP complexes. PLoS One. 2013; 8:e75836.

67. Huang W, Suzuki K, Nagase H, Arumugam S, Van Doren SR, Brew K. Folding and characterization of the amino-terminal domain of human tissue inhibitor of metalloproteinases-1 (TIMP-1) expressed at high yield in E. coli. FEBS Lett. 1996; 384:155-61.

68. Arkadash V, Yosef G, Shirian J, Cohen I, Horev Y, Grossman M, Sagi I, Radisky ES, Shifman JM, Papo N. Development of High Affinity and High Specificity Inhibitors of Matrix Metalloproteinase 14 through Computational Design and Directed Evolution. J Biol Chem. 2017; 292:3481-95.

69. Deryugina EI, Ratnikov B, Monosov E, Postnova TI, DiScipio R, Smith JW, Strongin AY. MT1-MMP initiates activation of pro-MMP-2 and integrin alphavbeta3 promotes maturation of MMP-2 in breast carcinoma cells. Exp Cell Res. 2001; 263:209-23.

70. Lu KV, Jong KA, Rajasekaran AK, Cloughesy TF, Mischel PS. Upregulation of tissue inhibitor of metalloproteinases (TIMP)-2 promotes matrix metalloproteinase (MMP)-2 activation and cell invasion in a human glioblastoma cell line. Lab Invest. 2004; 84:8-20.

71. Devy L, Huang L, Naa L, Yanamandra N, Pieters H, Frans N, Chang E, Tao Q, Vanhove M, Lejeune A, van Gool R, Sexton DJ, Kuang G, et al. Selective inhibition of matrix metalloproteinase-14 blocks tumor growth, invasion, and angiogenesis. Cancer Res. 2009; 69:1517-26.

72. Hagemann C, Anacker J, Ernestus RI, Vince GH. A complete compilation of matrix metalloproteinase expression in human malignant gliomas. World J Clin Oncol. 2012; 3:67-79.

73. Puli S, Lai JC, Bhushan A. Inhibition of matrix degrading enzymes and invasion in human glioblastoma (U87MG) cells by isoflavones. J Neurooncol. 2006; 79:135-42. 
74. Schröpfer A, Kammerer U, Kapp M, Dietl J, Feix S, Anacker J. Expression pattern of matrix metalloproteinases in human gynecological cancer cell lines. BMC Cancer. 2010; 10:553.

75. Köhrmann A, Kammerer U, Kapp M, Dietl J, Anacker J. Expression of matrix metalloproteinases (MMPs) in primary human breast cancer and breast cancer cell lines: New findings and review of the literature. BMC Cancer. 2009; 9:188.

76. Balduyck M, Zerimech F, Gouyer V, Lemaire R, Hemon B, Grard G, Thiebaut C, Lemaire V, Dacquembronne E, Duhem T, Lebrun A, Dejonghe MJ, Huet G. Specific expression of matrix metalloproteinases 1, 3, 9 and 13 associated with invasiveness of breast cancer cells in vitro. Clin Exp Metastasis. 2000; 18:171-78.

77. Cepeda MA, Pelling JJ, Evered CL, Williams KC, Freedman Z, Stan I, Willson JA, Leong HS, Damjanovski $\mathrm{S}$. Less is more: low expression of MT1-MMP is optimal to promote migration and tumourigenesis of breast cancer cells. Mol Cancer. 2016; 15:65.

78. Figueira RC, Gomes LR, Neto JS, Silva FC, Silva ID, Sogayar MC. Correlation between MMPs and their inhibitors in breast cancer tumor tissue specimens and in cell lines with different metastatic potential. BMC Cancer. 2009; 9:20.

79. Byun HJ, Hong IK, Kim E, Jin YJ, Jeoung DI, Hahn JH, Kim YM, Park SH, Lee H. A splice variant of CD99 increases motility and MMP-9 expression of human breast cancer cells through the AKT-, ERK-, and JNK-dependent AP-1 activation signaling pathways. J Biol Chem. 2006; 281:34833-47.

80. Sarkar CA, Dodevski I, Kenig M, Dudli S, Mohr A, Hermans E, Plückthun A. Directed evolution of a G proteincoupled receptor for expression, stability, and binding selectivity. Proc Natl Acad Sci U S A. 2008; 105:14808-13.

81. Oshima S, Karrer EE, Paidhungat MM, Neighbors M, Chapin SJ, Fan RA, Reed MA, Wu K, Wong C, Chen Y, Whitlow M, Anderson FA, Bam RA, et al. ASP2408 and ASP2409, novel CTLA4-Ig variants with CD86-selective ligand binding activity and improved immunosuppressive potency, created by directed evolution. Protein Eng Des Sel. 2016; 29:159-67.

82. Douthwaite J, Moisan J, Privezentzev C, Soskic B, Sabbah S, Cohen S, Collinson A, England E, Huntington C, Kemp B, Zhuang L, Hudak S, Rees DG, et al. A CD80-Biased CTLA4-Ig Fusion Protein with Superior In Vivo Efficacy by Simultaneous Engineering of Affinity, Selectivity, Stability, and FcRn Binding. J Immunol. 2017; 198:528-37.

83. Silverman AP, Levin AM, Lahti JL, Cochran JR. Engineered cystine-knot peptides that bind $\alpha(\mathrm{v}) \beta(3)$ integrin with antibody-like affinities. J Mol Biol. 2009; 385:1064-75.

84. Kimura RH, Levin AM, Cochran FV, Cochran JR. Engineered cystine knot peptides that bind alphavbeta3, alphavbeta5, and $\alpha 5 \beta 1$ integrins with low nanomolar affinity. Proteins. 2009; 77:359-69.
85. Glotzbach B, Reinwarth M, Weber N, Fabritz S, Tomaszowski M, Fittler H, Christmann A, Avrutina O, Kolmar H. Combinatorial optimization of cystineknot peptides towards high-affinity inhibitors of human matriptase-1. PLoS One. 2013; 8:e76956.

86. Alakus H, Grass G, Hennecken JK, Bollschweiler E, Schulte C, Drebber U, Baldus SE, Metzger R, Hölscher AH, Mönig SP. Clinicopathological significance of MMP-2 and its specific inhibitor TIMP-2 in gastric cancer. Histol Histopathol. 2008; 23:917-23.

87. Deryugina EI, Quigley JP. Matrix metalloproteinases and tumor metastasis. Cancer Metastasis Rev. 2006; 25:9-34.

88. Paiva KB, Granjeiro JM. Bone tissue remodeling and development: focus on matrix metalloproteinase functions. Arch Biochem Biophys. 2014; 561:74-87.

89. Ratnikov BI, Cieplak P, Gramatikoff K, Pierce J, Eroshkin A, Igarashi Y, Kazanov M, Sun Q, Godzik A, Osterman A, Stec B, Strongin A, Smith JW. Basis for substrate recognition and distinction by matrix metalloproteinases. Proc Natl Acad Sci U S A. 2014; 111:E4148-55.

90. Cieplak P, Strongin AY. Matrix metalloproteinases - From the cleavage data to the prediction tools and beyond. Biochim Biophys Acta. 2017; 1864:1952-63.

91. Batra J, Robinson J, Soares AS, Fields AP, Radisky DC, Radisky ES. Matrix metalloproteinase-10 (MMP-10) interaction with tissue inhibitors of metalloproteinases TIMP-1 and TIMP-2: binding studies and crystal structure. J Biol Chem. 2012; 287:15935-46.

92. Butler GS, Hutton M, Wattam BA, Williamson RA, Knäuper V, Willenbrock F, Murphy G. The specificity of TIMP-2 for matrix metalloproteinases can be modified by single amino acid mutations. J Biol Chem. 1999; 274:20391-96.

93. Bahudhanapati H, Zhang Y, Sidhu SS, Brew K. Phage display of tissue inhibitor of metalloproteinases-2 (TIMP2): identification of selective inhibitors of collagenase-1 (metalloproteinase 1 (MMP-1)). J Biol Chem. 2011; 286:31761-70.

94. Williamson RA, Bartels H, Murphy G, Freedman RB. Folding and stability of the active N-terminal domain of tissue inhibitor of metalloproteinases-1 and -2. Protein Eng. 1994; 7:1035-40.

95. Cohen I, Kayode O, Hockla A, Sankaran B, Radisky DC, Radisky ES, Papo N. Combinatorial protein engineering of proteolytically resistant mesotrypsin inhibitors as candidates for cancer therapy. Biochem J. 2016; 473:1329-41.

96. Chao G, Lau WL, Hackel BJ, Sazinsky SL, Lippow SM, Wittrup KD. Isolating and engineering human antibodies using yeast surface display. Nat Protoc. 2006; 1:755-68.

97. Ogata H, Decaneto E, Grossman M, Havenith M, Sagi I, Lubitz W, Knipp M. Crystallization and preliminary X-ray crystallographic analysis of the catalytic domain of membrane type 1 matrix metalloproteinase. Acta Crystallogr F Struct Biol Commun. 2014; 70:232-35. 